

\section{DISCLAIMER}

This report was prepared as an account of work sponsored by an agency of the United States Government. Neither the United States Government nor any agency Thereof, nor any of their employees, makes any warranty, express or implied, or assumes any legal liability or responsibility for the accuracy, completeness, or usefulness of any information, apparatus, product, or process disclosed, or represents that its use would not infringe privately owned rights. Reference herein to any specific commercial product, process, or service by trade name, trademark, manufacturer, or otherwise does not necessarily constitute or imply its endorsement, recommendation, or favoring by the United States Government or any agency thereof. The views and opinions of authors expressed herein do not necessarily state or reflect those of the United States Government or any agency thereof. 


\section{DISCLAIMER}

Portions of this document may be illegible in electronic image products. Images are produced from the best available original document. 


\title{
NOISE RADIATION FROM ENERGY CENTER COOLING TOWERS
}

\author{
J. Zakaria* and F. Moore** \\ *Research Assistant and ${ }^{* *}$ Professor \\ Sibley School of Mechanical \& Aerospace Engineering \\ Cornell University
}

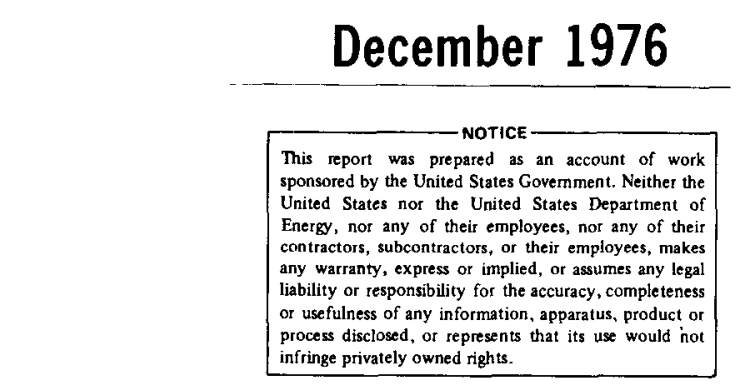

POLICY ANALYSIS DIVISION

NATIONAL CENTER FOR ANALYSIS OF ENERGY SYSTEMS

BROOKHAVEN NATIONAL LABORATORY

ASSOCIATED UNIVERSITIES, INC.

UPTON, NEW YORK 11973

Prepared for the

OFFICE OF SPECIAL STUDIES, UNITED STATES NUCLEAR REGULATORY COMMISSION,

AND THE UNITED STATES DEPARTMENT OF ENERGY

UNDER CONTRACT NO. EY-76-C-02-0016 


\section{N O T I G E}

This report was prepared as an account of work sponsored by the United States Government. Neither the United States nor the United States Department of Energy (DOE), nor any of their employees, nor any of their contractors, subcontractors, or their employees, makes any warranty, express or implied, or assumes any legal liability or responsibility for the accuracy, completeness or usefulness of any information, apparatus, product or process disclosed, or represents that its use would not infringe privately owned rights.

Printed in the United States of America Available from

National Technical Information Service U.S. Department of Commerce

5285 Port Royal Road Springfield, VA 22161

Price: Printed Copy $\$ 5.25$; Microfiche $\$ 3.00$

May 1978 500 copies 
FOREWORD

This study is one of a continuing series of reports on Energy Center Siting sponsored by the U.S. Nuclear Regulatory Commission and the Division of Technology Overview of the U.S. Energy Research and Development Administration, prepared by the Brookhaven National Laboratory Energy Policy Analysis Division.

To date, the Brookhaven National Laboratory energy center research effort has focused on an evaluation of a hypothetical Nuclear Energy Center in New Jersey and the development and application of specific analytical tools necessary for policy assessments. It is to the latter area that this report is addressed.

Other reports in this series include:

Energy Policy Analysis Group, et al. "A Preliminary Assessment of a Hypothetical Nuclear Energy Center in New Jersey", BNL-50465, Nov. 1975.

P.M. Meier and D. Morell "Issues in Clustered Nuclear Siting: A Comparison of a Hypothetical Nuclear Energy Center in New Jersey with Dispersed Nuclear Siting", BNL-50561.

Regional Science Department, University of Pennsylvania, "Regional Economic Impacts of Nuclear Power Plants", BNL-50562. P. M. Meier "Optimization of Water Conveyance Systems for Nuclear Energy Center", BNL-50563.

S. Linke and D. Chu, "Transmission Studies of Dispersed vs. Clustered Generating Facilities", BNL-50565. 
Noise radiation from the cooling towers of clustered and dispersed arrays of cooling towers for large power plants is presented, and a procedure presented for the prediction of noise levels at some distance from the rim of single isolated tower. Two types of cooling systems, namely mechanical-draft wet and natural-draft wet cooling towers, are considered, which are assumed to act as the sole source of noise generation in power plants.

The procedure for the prediction of noise levels from single isolated towers is then extended to determine noise levels at some point on the site boundary of energy centers being proposed for the future.

It is concluded that if one wishes to minimize the area impacted by objectionable noise levels, then for concentrated power centers either mechanical-draft or natural-draft towers may be chosen, while for more widely dispersed centers natural-draft systems must be recommended. Special emphasis has been placed upon the A-weighted sound levels, which correlate well with human sound perception. One dimensional free wave spreading and atmospheric absorption are the attenuation factors taken into account. 
Nomenclature . . . . . . . . . . . . . . . . $\frac{\text { Page }}{\mathbf{v i}}$

1. Introduction . . . . . . . . • . . • . . . . 1

2. Noise Radiation from Single Isolated Cooling Towers . . . . 3

2.1 Natura1-Draft Wet Cooling Tower Noise Estimation . . . 3

2.2 Mechanical-Draft Wet Cooling Tower Noise Estimation . . 12

2.3 Discussion • • • • • • • • • • • • • • . . 17

3. Noise Radiation From Cooling Towers of Power Parks . . . . 20

3.1 Natura1-Draft Wet Towers . . . . . . . . . . 22

3.2 Mechanical-Draft Wet Towers . . . . . . . . 25

3.3 Discussion . . . . . . . . • . • . • . . . 25

4. Noise Radiation From Cooling Towers of the Dispersed Power

Plant Sites . . . . . . . . . . . . . . . . 27

4.1 Geometrical Configuration of Array of Towers . . . . 27

4.2 Estimation of Noise Levels at the Point 0 . . . . . 29

4.3 Noise Level Contour . . . . . . . • . • . . . 32

4.4 Simplified Geometrical Approximation for the Dispersed Array of Towers • . . . . . . . . . . . 34

5. Comparison of a Concentrated Power Center with the Dispersed Generating Stations . . . . . . . . . . . . 43

6. Conclusions . . . . . . . . . . . . . . . . 51 Appendix: Discussion of the form $\Delta$. . $^{\circ}$. . . . . . . 53

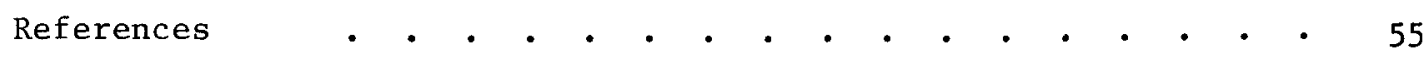


A

$A_{p}, A_{p}^{\prime}$

a

$B, B^{\prime}$

b

C

c

D

$h, h^{\prime}$

hp

I

$(i, j)$

k

L

$\ell$

$\mathrm{L}_{\omega}$

n

0

$\mathrm{O}^{\prime}$

$\mathrm{p}$

$\mathrm{P}_{\mathrm{A}}$

$\mathrm{p}$

R

r

$\mathrm{S}$
Subscript for A-weighting.

Atmospheric absorption and A-weighting parameters.

The numerical values are given in the Appendix.

Subscript for atmospheric attenuation.

Tower constants for natural and mechanical draft towers respectively.

Constant $=1 / 3,000$ for $\mathrm{L}$ in meters $=1 / 9,840$ for $\mathrm{L}$ in

feet.

Radius of power park site boundary, Figure 6 .

Sound speed in air.

Natural-draft cooling tower parameter.

Natural-draft cooling tower parameters.

Rated fan horse power. Its value is 3,625 for a typical

mechanical-draft tower for a $600 \mathrm{MW}$ electric generating

station.

Average intensity of sound.

Grid point, Figures 9,10 and 17 .

Number of frequency bands in the noise spectrum.

Radius of the innermost circle for the approximation of the

location of dispersed towers, Figure 17.

Side of the square generating the mesh-work, Figures 9 and 10 .

Sound power level for mechanical-draft towers.

Maximum number assigned to $i$. Total number of towers = $4 \sum_{i=1}^{n}(2 i-1)$.

Point of interest, Figures 6 and 9 .

point of interest, Figure 17 .

Sound Pressure

A-weighted root mean square sound pressure.

Number assigned to the frequency band. See also Appendix.

Natural-draft tower base radius, Figure 1.

Radius of the power park, Figure 6 .

Distance from the source to the point of interest.

Also used as a subscript. 


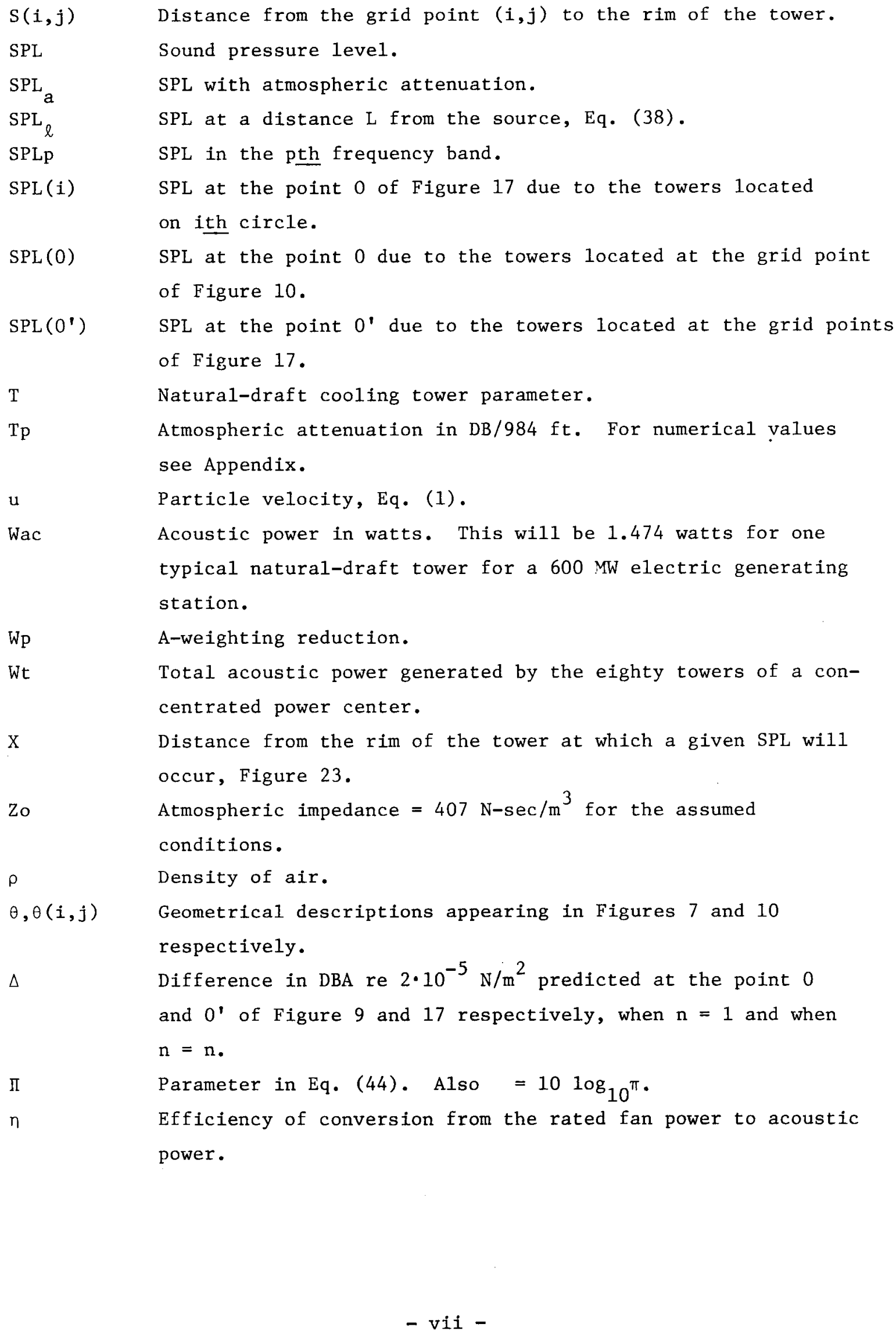




\subsection{Background}

This report is one of several technical studies conducted by the BNL Regional Studies Program in connection with an evaluation of a hypothetical nuclear energy center (NEC) in Ocean County, New Jersey. As such, it addresses only the rather narrow technical area of cooling tower noise; the comprehensive evaluation of al1 facets of the NEC is reported in a separate study, to which the reader is referred for further background. *

A number of reasons justified the detailed analysis of cooling tower noise. The main reason is that concern over noise emerged very early in our study effort as one of the key public concerns. Since the presence of cooling towers in close proximity to the many beaches of the New Jersey Atlantic coastline raised great apprehension on the part of the recreation industry, some effort was merited in addressing the noise and visibility issues in some detail. Unfortunately the configuration of up to 40 reactors at a single site raised a number of technical problems in noise assessment, and it is to the development of an appropriate noise prediction model that this report is addressed.

It should be pointed out that the intent of our New Jersey NEC analyses, which were conducted in support of the U.S. Nuclear Regulatory Commission Nuclear Energy Center Site Survey (NECSS), was to inject a local and regional perspective into the broad national assessment of energy centers; since only be reference to specific sites could many of the technical, environmental, institutional and socioeconomic issues be adequately addressed. Indeed, in addition to the New Jersey study area a number of other potential areas were selected throughout the U.S. for more specific analysis, each typical of a representative set of siting attributes. Thus neither Ocean County, nor any of the other surrogate sites, is recommended for consideration for actual construction of an NEC; nor does the selection of study areas imply any judgement of desirability.

\footnotetext{
${ }^{*}$ P. Meier and D. Morel1 "Issues in Clustered Nuclear Siting: A Comparison of a Hypothetical Energy Center in New Jersey with Dispersed Nuclear Siting", BNL 50561.
} 


\subsection{Scope of Report}

In Chapter 2 we present a procedure for the prediction of noise levels at some distance from the rim of the natural-draft as well as mechanicaldraft wet cooling towers for a typical $600 \mathrm{MW}$ electric generating station. For natural-draft systems, one wet tower of base radius of $200 \mathrm{ft}$ has been considered. A schematic of such a tower is shown in Figure 1.

The technique for the prediction of noise levels from single isolated towers is extended further in Chapter 3 to noise radiation from energy center cooling towers. Initially the center is assumed to be of 48 GW capacity located at the center of the total site area (the "clustered" case).

At this point it should be mentioned that noise levels below 45 DBA are generally acceptable. If the reactors are more widely dispersed within the energy center, then the noise levels within the area of the dispersed tower sources may fall below $45 \mathrm{DBA}$, and hence acceptable. This situation is taken into account in Chapter 4 where the 1 istener is placed among and surrounded by power plants, which themselves are much farther apart, or dispersed, than in the clustered case.

Considering the area impacted by a given level of objectionable noise of $45 \mathrm{DBA}$, some interesting comparisons can be made of the results developed in Chapters 3 and 4, a task addressed in Chapter 5. 
In order to analyze the problem of noise radiation from an area with uniformly distributed acoustic power sources, the behavior of sound pressure level (SPL) with increasing distance from a single isolated tower will be studied first. The analytical procedure adopted for the prediction of noise levels is presented in the following pages. Mechanical and natural-draft tower noise has been dealt with separately although the prediction technique is the same for both the cases.

\subsection{Natural-Draft Wet Tower Noise Estimation}

The first step consists of the determination of cooling tower parameters such as dimensions, water flow rate, etc. Ref. (1) suggests two natural-draft wet cooling towers for a 1,200 MW Power Plant. For the present analysis a $600 \mathrm{MW}$ unit is considered for which, also according to Ref. (1), one tower of base diameter $400 \mathrm{ft}$ would be sufficient. The overall dimensions for a counterflow tower, inferred from Ref. (2), for a base diameter of $400 \mathrm{ft}$, are presented in Figure 1. The cooling water flow rate in this tower from Ref. (1) would be $620 \mathrm{cfs}$ or $17,564 \mathrm{kgs}$.

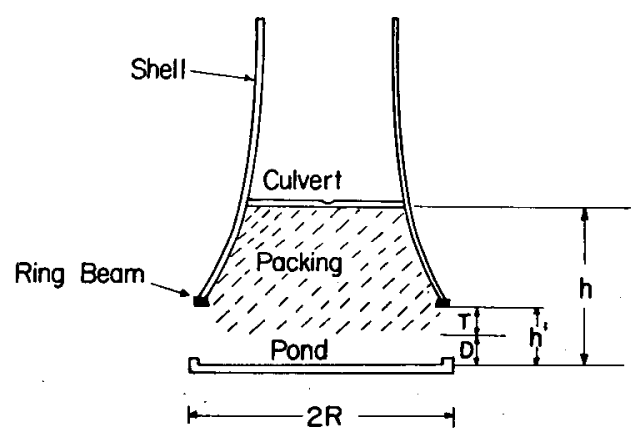

$$
\begin{aligned}
& \text { Cooling water flow rate }=17,564 \mathrm{Kg} / \mathrm{s}=620 \mathrm{cfs} \\
& \mathrm{h}=60 \mathrm{ft}=18.32 \mathrm{~m} \\
& T=37 \mathrm{ft}=11.3 \mathrm{~m} \\
& D=14 \mathrm{ft}=4.3 \mathrm{~m} \\
& R=200 \mathrm{ft}=61 \mathrm{~m}
\end{aligned}
$$

Figure 1. Natural-draft wet tower for a $600 \mathrm{MW}$ Power Plant. 
At this point a brief review of the theoretical background for the estimation of noise levels might be helpful. It should be emphasized that in the present analysis freely progressing one dimensional sound waves have been assumed. We now define the average intensity of sound, $I$, as the energy that flows through a unit area in a unit time, in the direction of the sound wave propagation. This intensity is the time average of the product of the sound pressure and the particle velocity measured in the direction of the wave propagation. Thus

$$
\mathrm{I}=\overline{\mathrm{P} \times \mathrm{u}}
$$

where $\mathrm{P}=$ sound pressure in $\mathrm{N} / \mathrm{m}^{2}$

$\mathrm{u}=$ particle velocity in $\mathrm{m} / \mathrm{s}$ associated with the to and from motions of the air molecules, which always occur along a line parallel to the direction of propagation. The product $\overline{\mathrm{Px}}$ can be shown to be equal to $\mathrm{P}_{\mathrm{rms}}^{2} / \rho \mathrm{c}$ or

$$
I=\frac{P_{\text {rms }}^{2}}{\rho c}
$$

where $\mathrm{P}_{\text {rms }}=$ root mean square sound pressure

$\rho=$ density of air

$c=$ sound speed in air.

Sound pressure level at some point at a distance $S$ from the source is given, by definition, by the following equation:

$$
\mathrm{SPL}_{\mathrm{S}}=10 \log _{10}\left[\frac{\mathrm{P}_{\mathrm{rms}}^{2} \text { at } \mathrm{S}}{\left(2.10^{-5}\right)^{2}}\right] \mathrm{DB} \text { re } 2 \cdot 10^{-5} \mathrm{~N} / \mathrm{m}^{2}
$$

In order to find the sound energy intensity at some distance $S$ from the rim of a natural-draft wet cooling tower, Ellis, in Ref. (3), has developed the following relationship for uniform hemispherical radiation ${ }^{*}$ :

$$
\mathrm{P}_{\mathrm{A}}^{2}=\frac{\mathrm{W}_{\mathrm{ac}} \mathrm{Z}_{\mathrm{o}}}{\pi^{2}\left(\mathrm{~S}^{2}+2 \mathrm{SR}\right)} \tan \sqrt[-1]{\frac{\mathrm{S}+2 \mathrm{R}}{\mathrm{S}}}\left(\mathrm{N} / \mathrm{m}^{2}\right)^{2}
$$

where $\mathrm{P}_{\mathrm{A}}=\mathrm{A}$-weighted root mean square sound pressure at $\mathrm{S}$. from the rim of the tower.

\footnotetext{
* It is assumed in Ref. (3) that the noise is generated by a ring of falling water around the edge of the pond (Figure 1), and that any noise generated inside this ring is prevented from escaping by reflection, refraction and absorption by the packing and falling water.
} 


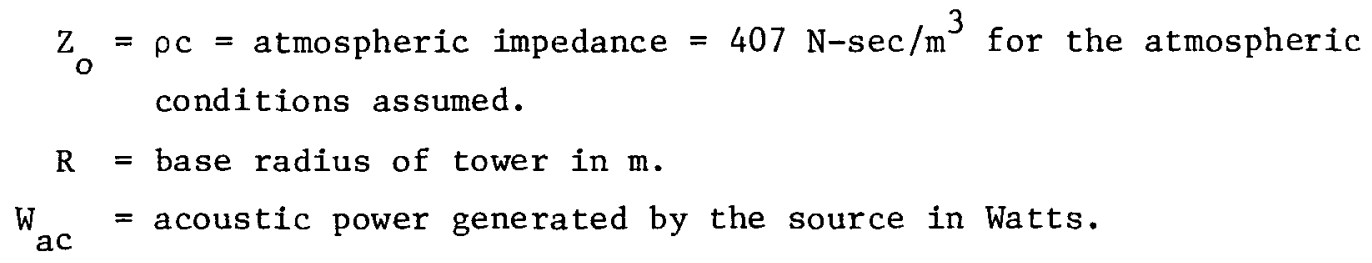

A brief comment on the behavior of eq. (4) when $S \gg R$ may be helpful. For this condition eq. (4) reduces to

$$
\mathrm{P}_{\mathrm{A}}^{2}=\frac{\mathrm{W} \mathrm{ac}^{\mathrm{Z}} \mathrm{o}}{4 \pi \mathrm{S}^{2}}
$$

Eq. (5) appears to describe a sperical radiation of the total acoustic power $W_{\text {ac }}$ generated by the splashing of water inside the tower. This contradicts our previous statement that Eq. (4) is derived on the basis of a uniform hemispherical radiation of noise. In fact there is no contradiction at all, for at $S \gg R$, the acoustic power generated at the far side of the tower rim is practically blocked by the structure of the tower from affecting the point of observation. Only that half of the total acoustic power $W_{\text {ac }}$, emanating from the visible side of the tower, actually produces impact at the point of observation. Therefore for $S$ large compared to $R$, half of the total acoustic energy radiating hemispherically is mathematically equivalent to the total acoustic energy radiating spherical1y.

The determination of $\mathrm{P}_{\mathrm{A}}$ in Eq. (4) can be accomplished by first evaluating $W_{\text {ac }}$ Ellis has presented the following equation which relates the acoustic power $W_{\text {ac }}$ with the tower parameters:

$$
\mathrm{W}_{\mathrm{ac}}=\operatorname{Mh}\left\{.95 \cdot 10^{-5}\left(\frac{\mathrm{T}}{\mathrm{h}}\right)^{2}+1.8 \cdot 10^{-5}\left(\frac{\mathrm{D}}{\mathrm{h}}\right)^{2}\right\}
$$


where $M$ is the flow rate of cooling water in $\mathrm{Kg} / \mathrm{s}$, and $\mathrm{T}, \mathrm{h}, \mathrm{D}$ are the physical dimensions of tower (see Figure 1). For our tower for a $600 \mathrm{MW}$ power station, from Eq. (6) one obtains

$$
\mathrm{W}_{\mathrm{ac}}=1.474 \text { Watts }
$$

This implies an efficiency of water pumping power for conversion into sound power of

$$
n=\frac{1.474}{17,564 \times 18.32 \times 9.8}=.47 \cdot 10^{-6}
$$

This value of $\eta$ is quite reasonable. In fact measured conversion efficiencies stated by E11is in Ref. (3) for natural-draft wet cooling towers range from 0.37 to 0.81 PPM. The A-weighted SPL can now be found by using the value of $\mathrm{W}_{\mathrm{ac}}$ from $\mathrm{Eq}$. (6) in Eq. (4), and then substituting ${ }_{\mathrm{A}}$ from Eq. (4) for $\mathrm{P}_{\mathrm{rms}}$ in $\mathrm{Eq} \cdot$ (3):

$$
\mathrm{SPL}_{\mathrm{S}}=10 \log _{10}\left\{\frac{\mathrm{P}_{\mathrm{A}}^{2}}{\left(2 \cdot 10^{-5}\right)^{2}}\right\} \quad \mathrm{DBA} \text { re } 2 \cdot 10^{-5} \mathrm{~N} / \mathrm{m}^{2}
$$

The above equation essentially results in the A-weighted, unattenuated SPL. In order to find the A-weighted sound levels with atmospheric attenuation, we first break the $\mathrm{SPL}_{S}$ into the individual sound levels in the octave bands of the spectrum. These octave band levels can then be reduced by the respective DB reduction due to the atmospheric absorption. The resulting sound intensity in each band is then added to yield the net A-weighted and attenuated sound levels actually reaching a distance $S$ from the rim of a natural-draft tower. The overall procedure for the computation of sound levels at some distance from the rim of a naturaldraft tower is presented in the following example:

Example 2.1:

Given a point $100 \mathrm{ft}(30.5 \mathrm{~m})$ from the rim of the natural-draft tower in Figure 1, one wishes to find the A-weighted sound levels with atmospheric attenuation at this point. 
With $S=30.5$, Eq. (4) yields

$$
\mathrm{P}_{\mathrm{A}}^{2}=.01498\left(\mathrm{~N} / \mathrm{m}^{2}\right)^{2}
$$

or

$$
\mathrm{P}_{\mathrm{A}}=.1222 \mathrm{~N} / \mathrm{m}^{2}
$$

from Eq.(7) one obtains

$$
\mathrm{SPL}_{\mathrm{S}}(\mathrm{S}=30.5)=75.7 \mathrm{DBA} \text { re } 2 \cdot 10^{-5} \mathrm{~N} / \mathrm{m}^{2}
$$

The noise spectrum is considered next. It is quite reasonable to assume that the overall shape of the spectrum is nearly the same for different towers and for various distances from the tower source. Table 1, from Ref. (3), is used in our analysis.

Table 1

Natura1-Draft Wet Cooling Tower Noise Spectrum

Average octave band levels relative to A-weighted SPL in DB re $2 \cdot 10^{-5} \mathrm{~N} / \mathrm{m}^{2}$

Center Frequency

$\begin{array}{lllllll}.125 & .25 & .5 & 1 & 2 & 4 & 8\end{array}$

$(\mathrm{KHz})$

Level at Tower Rim

$$
\begin{array}{lllllll}
-19.4 & -19.8 & -13.0 & -7.8 & -6.3 & -4.3 & -7.2
\end{array}
$$

The A-weighted sound level of Eq. (8) can now be resolved by using Table 1 into sound levels in each frequency band. For example, the sound level in the frequency band of $1 \mathrm{KHz}$ will be 75.7-7.8 $=68.9 \mathrm{DB}$. Table 2 presents the spectrum at $S=100 \mathrm{ft}$ from the tower rim.

The effect of atmospheric absorption is now taken into account. Table 3, which includes data for mechanical-draft tower noise atmospheric conditions of $60^{\circ} \mathrm{F}$ and $70 \%$ relative humidity, is extracted from Ref. (4). 
Table 2

Noise Spectrum of a Natural-Draft Wet Cooling Tower at

$\mathrm{S}=100 \mathrm{Ft}$ from Tower Rim (Without Atmospheric Absorption)

$\begin{array}{llllllll}\text { Center frequency } & .125 & .25 & .5 & 1 & 2 & 4 & 8\end{array}$

$(\mathrm{KHz})$

$\begin{array}{llllllll}\text { Average Octave } & 66.3 & 65.9 & 62.7 & 68.9 & 69.4 & 71.4 & 68.5\end{array}$

Tab1e 3

Atmospheric Absorption Rate

$\begin{array}{llllllllllll}\text { Center Frequency } & .05 & .1 & .125 & .2 & .25 & .5 & 1 & 2 & 4 & 8\end{array}$ $(\mathrm{KHz})$

Atmospheric Absorption

$$
\begin{array}{llllllllll}
- & - & - & .01 & .014 & .7 & 1.4 & 3.0 & 7.7 & 14.4
\end{array}
$$

The sound levels actually reaching a point $100 \mathrm{ft}$ from the rim of the tower of Figure 1, can now be obtained by reducing the levels of Table 2 by the respective atmospheric absorptions presented in Table 3. For example, for an octave band center frequency of $1 \mathrm{KHz}$, the sound level at a distance $\mathrm{S}$ from the rim of the tower will be:

$$
\begin{aligned}
& \mathrm{SPL}_{\mathrm{a}} \cdot(\text { for a center frequency of } 1 \mathrm{KHz} \text { ) } \\
& =\mathrm{SPL}_{\mathrm{S}}-1.4 \times \mathrm{S} / 300-7.8 \\
& \uparrow \uparrow \uparrow \uparrow \\
& \text { Eq. (7) Table } 3 \quad \text { Table } 1
\end{aligned}
$$


where the subscript a in Eq. (9) refers to sound levels with atmospheric attenuation. For the whole spectrum the results are presented in Table 4 .

Table 4

A-Weighted Sound Levels with Atmospheric Attenuation at $S=100 \mathrm{Ft}$. , From the Rim of the Natural-Draft Cooling Tower for a

$600 \mathrm{MW}$ Station

\begin{tabular}{|c|c|c|c|c|c|c|c|c|}
\hline $\begin{array}{l}\text { Center } \\
\text { frequency } \\
\quad(\mathrm{KHz})\end{array}$ & .125 & .25 & .5 & 1 & 2 & 4 & 8 & $\begin{array}{l}\text { DBA re } \\
2 \cdot 10^{-5} \\
\mathrm{~N} / \mathrm{m}^{2}\end{array}$ \\
\hline \multicolumn{9}{|c|}{ Octave band } \\
\hline $\begin{array}{l}\text { leve1s } \\
\text { (DB) }\end{array}$ & 66.3 & 65.9 & 62.7 & 68.9 & 69.4 & 71.4 & 68.5 & 75.7 \\
\hline $\begin{array}{l}\text { Atmospheri } \\
\text { absorption } \\
\text { (DB) }\end{array}$ & - & .0014 & .0072 & .143 & .305 & .78 & 1.46 & \\
\hline $\begin{array}{l}\text { Predicted } \\
\text { levels }\end{array}$ & 66.3 & 65.89 & 62.69 & 68.76 & 69.09 & 70.62 & 67.04 & 73.9 \\
\hline
\end{tabular}

Finally, Tables 1 to 4 are combined to yield Table 5 representing the overall noise level prediction scheme at a distance $S$ from the rim of a natural-draft wet cooling tower of Figure 1.

Figure 2 shows sound levels calculated in this way for various distances from a natural-draft cooling tower (the mechanical-draft curves will be explained later.)

Figure 3 represents the A-weighted spectra representing the energies actually felt by the human ear at various octave band center frequencies. Note that as $\mathrm{S}$ increases, higher frequency contributions disappear from the spectra because of atmospheric absorption. 
Table 5

Prediction of A-Weighted SPL With Atmospheric Attenuation for A Natural-Draft Wet Tower for a $600 \mathrm{MW}$ Power P1ant

$$
\left(\mathrm{S}=100 \mathrm{ft} ; \mathrm{SPL}_{\mathrm{S}}=75.7 \mathrm{DB} \text { re } 2 \cdot 10^{-5} \mathrm{~N} / \mathrm{m}^{2}\right)
$$

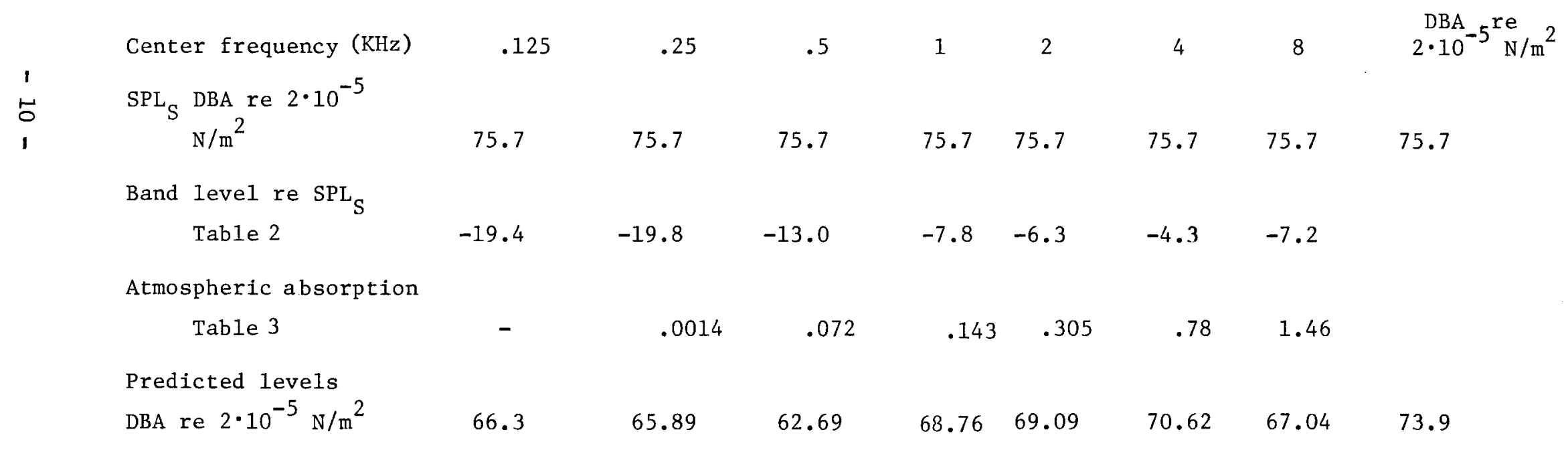




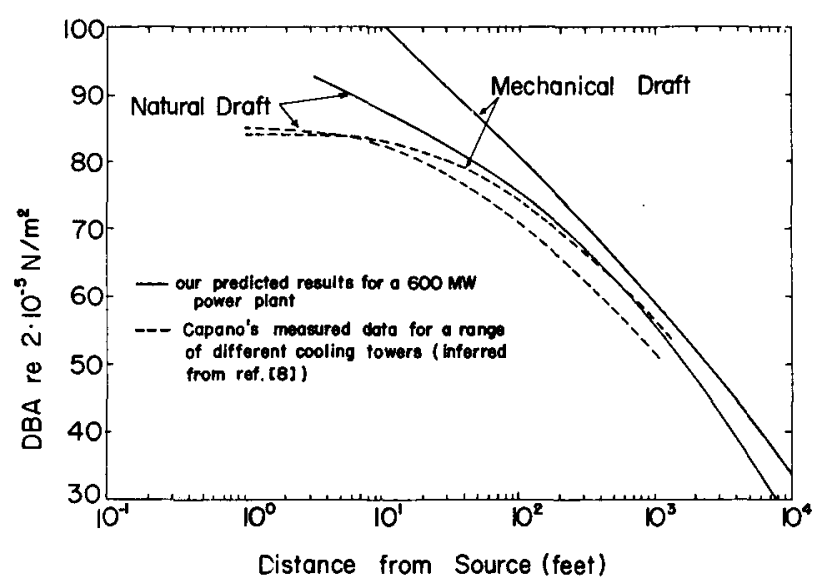

Figure 2. Behavior of sound pressure levels (with A-weighting and atmospheric absorption) with increasing distance from single isolated cooling towers. For mechanical-draft towers for a $600 \mathrm{MW}$ Power Plant, rated fan power $=3,625 \mathrm{hp}$; and an efficiency of conversion from rated fan power to acoustic power $=3 \mathrm{PPM}$. For natural-draft tower for a 600 MW Power Plant, data used is: one wet tower; cooling water flow rate $=23 \cdot 10^{6}$ gal per min; pumping head $=60 \mathrm{ft}$; tower base dia. $=400$ $f t$; efficiency of conversion from cooling water potential energy into acoustic power $=0.47 \mathrm{PPM}$.

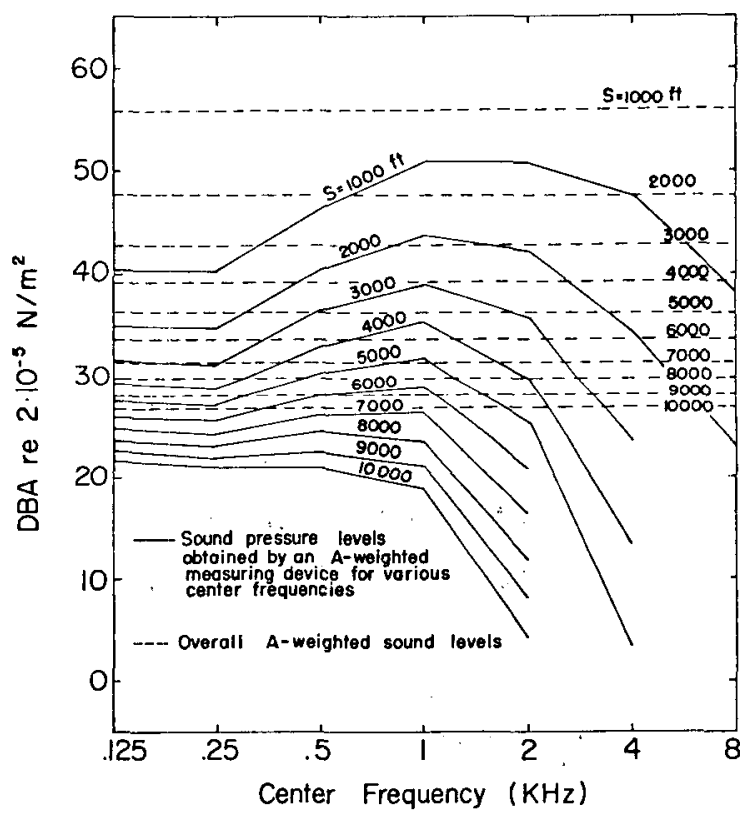

Figure 3. A-weighted noise spectra at $\mathrm{S} f t$ from the natural-draft tower-for a $600 \mathrm{MW}$ Power Plant. 


\subsection{Mechanical-Draft Wet Cooling Tower Noise Estimation}

Dyer and Miller in Ref. (5) have suggested an efficiency of 3 PPM of the rated fan power for conversion into sound power, as a rough preliminary estimate for the noise generation from mechanical-draft wet cooling towers.

$$
L_{\omega} \simeq 105+10 \log (h p) \text { DB re } 10^{-13} \text { Watts }
$$

where

$$
\begin{aligned}
& \mathrm{L}_{\omega}=\text { sound power level of the source, } \\
& \mathrm{hp}=\text { rated fan horse power. }
\end{aligned}
$$

At $\mathrm{S}$ ft from the tower rim, and assuming a free sperical spreading, the SPL according to Dyer and Miller will be:

$$
\mathrm{SPL}_{\mathrm{S}}=\mathrm{L}_{\omega}-10 \log _{10}\left(4 \pi \mathrm{S}^{2}\right)
$$

Eqs. (10) and (11) can be combined to give

$$
\mathrm{SPL}_{\mathrm{S}}=10 \log _{10}\left\{\frac{10^{10 \cdot 5} \mathrm{hp}}{4 \pi \mathrm{S}^{2}}\right\} \quad \mathrm{DB} \text { re } 10^{-13} \text { watts }
$$

We should comment on the assumption of free sperical spreading in Eq. (11). On the basis of this assumption, Dyer and Miller (Ref.(5)). developed Eq.(10) for the mechanical-tower noise estimation. The constant number appearing on the right hand side of Eq. (10) is, in fact, a consequence of the assumption of free spherical spreading. This constant number will assume a different value if uniform hemispherical propagation of sound is assumed. Accepting the validity of Eqs. (10) and (11) in the actual physical situation, for a hemispherical spreading Eq. (10) will become

$$
L_{\omega}=102+10 \log _{10}(\mathrm{hp})
$$

The fact that the efficiency of conversion from the rated fan power to acoustic power is about $3 \mathrm{PPM}$, as stated by Dyer and Miller, can also be 
questioned in this context. Halving this efficiency to $1.5 \mathrm{PPM}$, and assuming hemispherical spreading would be mathematically equivalent to Eqs. (10) and (11). However, since Dyer and Miller have labeled the spreading of mechanical-draft tower noise as being spherical, we shall use the same term in this context in the present analysis.

We now proceed onwards from Eq. (12). It should be mentioned that in Eq. (7) we obtained directly the A-weighted sound level, while in $\mathrm{Eq}$. (12) we have yet to apply the A-weighting reduction in order to get DBA's instead of simply DB's. Figure 4, from Ref, (6), is a presentation of the sensitivity of the A-weighted measuring instruments. The data from this figure will be used for the A-weighting reduction. To do so, we first break the $\mathrm{SPL}_{\mathrm{S}}$ of $\mathrm{Eq}$. (12) into its respective components for the various center frequencies in the spectrum. The rest of the procedure for the prediction of the A-weighted noise levels with atmospheric attenuation is the same as presented in Section 2.1 for natural-draft towers except that an additional reduction of levels will be required in this case to account for the A-weighting.

We now present an example which shows the noise level prediction scheme for the mechanical-draft towers.

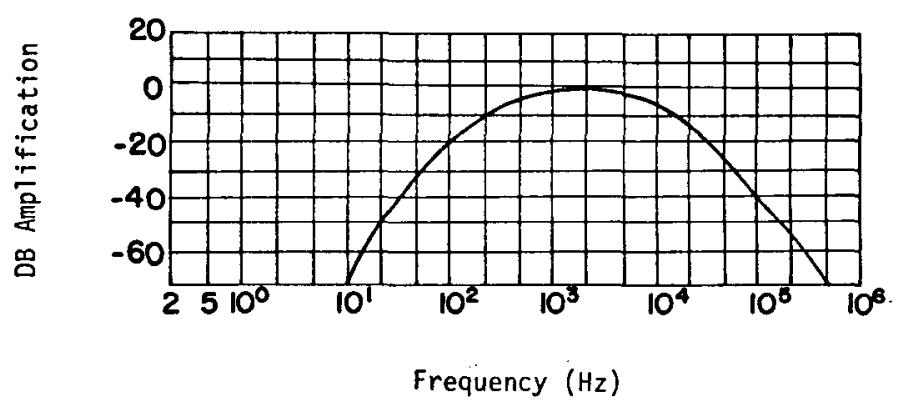

Figure 4. The internationally standardized A-weighting curve for sound level meters. 
Example 2.2:

Given a point 1,000 ft from a mechanical-draft tower for a $600 \mathrm{MW}$ power station, the total rated fan forse power for such a tower is 3,625 from Ref. (7). With $S=1,000 \mathrm{ft}$ and $\mathrm{hp}=3,625, \mathrm{Eq} \cdot$ (12) gives

$$
\mathrm{SPL}_{\mathrm{S}}(\mathrm{S}=1,000 \mathrm{ft})=69.6 \mathrm{DB} \text { re } 10^{-13} \text { Watts. }
$$

The next step is to break the SPL of the above equation to get the levels in the octave bands of mechanical-draft tower noise spectrum. This is done by using Table 6 prepared from Ref. (5).

\section{Table 6}

Mechanica1-Draft Wet Cooling Tower Noise Spectrum

Average octave band levels relative to the overall leve1 in $\mathrm{DB}$ re $10^{-13}$ Watts

$\begin{array}{lllllllll}\begin{array}{l}\text { Center frequency } \\ (\mathrm{KHz})\end{array} & .05 & .1 & .2 & .5 & 1 & 2 & 4 & 8 \\ \begin{array}{l}\text { Level at tower } \\ \text { rim }\end{array} & -5 & -6 & -8 & -11 & -15 & -17.5 & -21 & -27\end{array}$

It is worth mentioning that after reducing the $\mathrm{SPL}_{S}$ by the values of

Table 6 in a similar manner as we did for natural-draft towers, the resulting $\mathrm{DB}$ 's for each center frequency would be relative to $2 \cdot 10^{-5} \mathrm{~N} / \mathrm{m}^{2}$. Sound levels for each frequency band obtained as such can then be reduced to the A-weighted levels by using Table 7 which has been prepared from Figure 4 .

Table 7

Effect of A-Weighting

$\begin{array}{lllllllll}\begin{array}{l}\text { Center frequency } \\ \text { (KHz) }\end{array} & .05 & .1 & .2 & .5 & 1 & 2 & 4 & 8 \\ \begin{array}{l}\text { DBA re average } \\ \text { octave band levels }\end{array} & -30 & -20 & -10 & -3 & - & - & -1 & -3\end{array}$


Atmospheric attenuation is applied next by using Table 3. For example, consider the center frequency of $500 \mathrm{HZ}$. The A-Weighted predicted sound level at $\mathrm{S}$ ft from the source, with atmospheric absorption, will be:

$$
\begin{gathered}
\mathrm{SPL}_{\mathrm{a}} \quad \text { (for a center frequency of } 500 \mathrm{~Hz} \text { ) } \\
=\mathrm{SPL}_{\mathrm{S}}-.7 \times \mathrm{S} / 983-11-3 \\
\text { Eq. (12) Tab1e } 3 \quad \text { Table } 6 \text { Table } 7
\end{gathered}
$$

Finally, for the whole spectrum, Table 8 shows results for $S=1,000$ ft. Various stages involved in the prediction of the noise levels are presented.

The overall results for various $S$ are plotted in Figure 2 along with those for natural-draft towers. Figure 5 is a presentation of mechanical-draft wet tower noise spectrum, corresponding to Figure 3 for natural-draft.

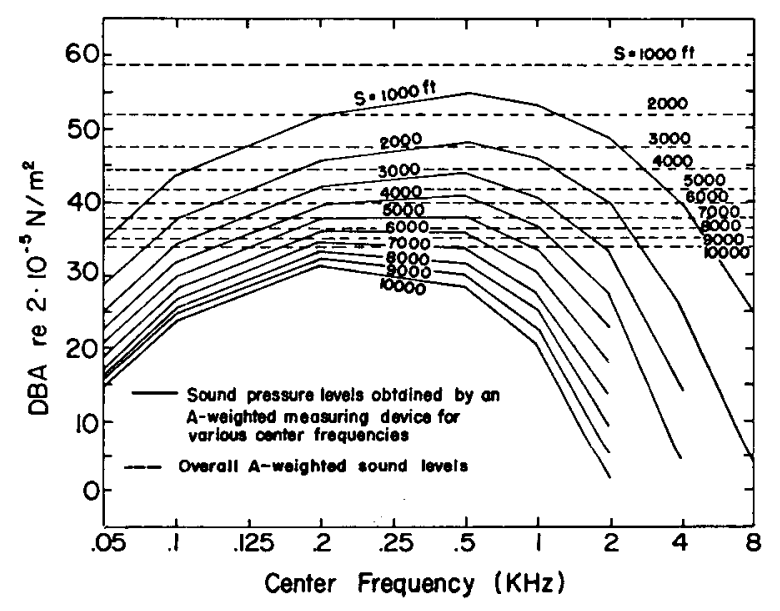

Figure 5. A-weighted noise spectra at $\mathrm{S}$ ft from the mechanical-draft tower for a $600 \mathrm{MW}$ Power Plant. 
Table 8

Prediction of A-Weighted SPL With Atmospheric Attenuation for Mechanical-Draft

Wet Towers for a $600 \mathrm{MW}$ Power Plant

$$
\left(\mathrm{S}=1,000 \mathrm{Ft} . ; \mathrm{SPL}_{\mathrm{S}}=69.6 \mathrm{DB} \text { re } 10^{-13} \text { Watts }\right)
$$

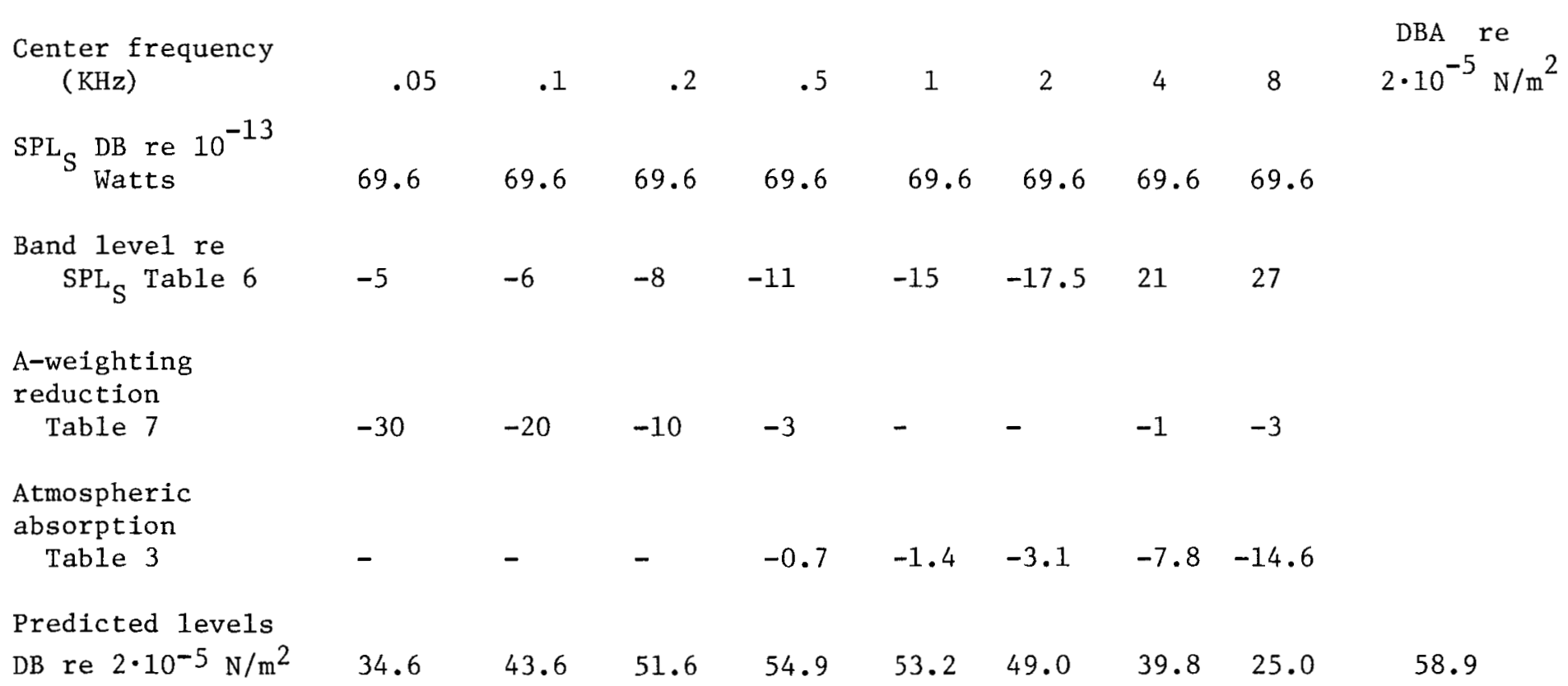




\subsection{Discussion}

Before proceeding on to the radiation of noise from energy center cooling towers, we should comment briefly on our predictions for single isolated towers. In Ref. (8) Capano has presented his experimentally measured sound pressure levels at varying distances from cooling tower sources. The mean values of Capano's measured envelope of data for a range of different mechanical- and natural-draft wet towers are plotted in dotted lines in Figure 2. Owing to the lack of data presented in Ref. (8) we are not in a position to interpret or generalize Capano's results. The dotted curves, however, give us some idea about what would be the overall behavior of sound pressure levels at increasing distances from the tower sources. When we compare our predicted curves (obtained as described in Sections 2.1 and 2.2 for a 600 MW power plant) with the measured (dotted) ones, we notice that for small distances from towers the overall shape of our curves is quite different from Capano's measured data. This becomes less significant for higher distances. The discrepancy arises mainly because of the assumptions involved in the mathematical analysis. These assumptions apply less accurately at small distances from tower rim. Our predicted results show that at small distances from tower rim the noise levels due to the mechanicaldraft towers will be considerably higher than natural-draft tower noise levels. This implies that acoustic power generation from mechanica1-draft towers will be much greater than the generation from their natural-draft counterparts. It will be interesting to note the difference steming from acoustic power generation from the two types of cooling systems being considered. As noted in Section 2.1, the acoustic power generated from natural-draft towers for a $600 \mathrm{MW}$ power plant would be 1.474 Watts. This power when substituted in Eq. (4) will lead to the A-Weighted sound levels. Acoustic power resulting in the unweighted SPL can be obtained by following the procedure opposite to that of the A-Weighting reduction scheme. This reduction scheme is illustrated in Section 2.2 for mechanical-draft towers. In this way, for natural-draft towers, the acoustic power leading to the unweighted sound levels was calculated to be 4.36 Watts. Correspondingly, for mechanical-draft towers, from Section 2.2 this power will be 8.1 Watts*, * 3 PPM conversion of the rated fan horsepower of 3,625 for a 600 MW p1ant leads to an acoustic power of 8.1 Watts. 
or about twice as great.

The above mentioned discrepancies between our estimates and Capano's measurements lead us to the point where we can suggest that there is a need for further investigation of both experimental and theoretical prediction procedure for noise levels, so that improved techniques could be devised for a better comprehension of the overall problem of noise radiation from cooling towers.

We note also from Figure 2 that noise levels of our natural-draft towers exhibit a shallower slope for distances up to $100 \mathrm{ft}$ as compared to the mechanical-draft tower noise. This can be explained by considering both atmospheric absorption and the sensitivity of the A-weighted measuring instruments simultaneously.

Atmospheric absorption increases linearly with distance and is greater at higher frequencies (see Table 3). The A-weighted sensitivity, Figure 4, is greatest in the range of 1 to $2 \mathrm{KHz}$. Therefore the higher frequency noise due to the splashing of water of natural-draft wet towers is sensed more efficiently by an A-weighting device. But at large distances, beyond 1,000 ft, the atmospheric absorption becomes predominant, causing the SPL to fall more rapidly. In the case of mechanical-draft tower noise, the A-weighting has less effect owing to the presence of lower frequencies. The almost uniform slope is thus due to the spherical attenuation of the acoustic energy intensity.

The environmental impact of noise radiation from single towers can be studied by first devising, according to Ref. (9), a Community Noise Equivalent Level (CNEL). In our case, since the noise will be continuous ( $24 \mathrm{hrs}$ a day), the CNEL correction to the predicted data will be zero. The same reference gives permissible levels for the following 'categories:
A - ultra critical areas (24 hrs)
$\frac{\mathrm{DBA}}{38}$
B - suburban residential (24 hrs)
43
C - urban residential (24 hrs)
48

Noise levels which do not exceed 45 DBA more than 30 min. per 24 hrs, 
have been classified in Ref. (10) as acceptable. With this information available, we observe from Figure 2 that for single isolated towers* for a $600 \mathrm{MW}$ power plant, a leve1 of $45 \mathrm{DBA}$ is reached at a distance of 2,500 ft from natura1-draft and at a distance of 3,800 ft from mechanicaldraft towers. These are therefore the safe distances from sources at which noise levels will not create any problem. It also appears that natural-draft systems will be much quieter.

* See Figures 1 and 2 for relevant physical parameters of towers. 
NOISE RADIATION ENERGY CENTER COOLING TOWERS

The noise problem from energy center cooling towers can be analyzed by the assumption of an energy center as an area of distributed acoustic power sources. This is done by averaging the total acoustic power over the whole area and then dividing the area into smaller elements. Each. element, or strip, can be thought of as a separate noise-generation source. And then by adopting the same technique as for the single towers, we can find the total sound intensity reaching at some point of interest by integrating the intensities from each area element over the entire area of power park.

It has been suggested that an energy center of 48 GW capacity would occupy a site of some $75 \mathrm{sq}$. miles. We assume for simplicity that this site is circular, of radius $C$. We then consider that power stations are uniformly distributed over a smaller concentric circular area of radius $r$. Figure 6 presents the overall configuration, with the shaded area representing the energy center, acting as a uniform source of acoustic power. We are interested in the tota1 sound pressure level at the point 0 located on the site boundary. The shaded area shown in Figure 7 , drawn along an arc of radius $S$, is a presentation of an area element mentioned above. All the sources in this area element will thus be approximately equidistant from 0 , and may as well be considered as a single acoustic generation source of strength:

$$
\mathrm{w}_{\mathrm{ac}}=2 \mathrm{~S} \theta\left(\frac{\mathrm{w}_{\mathrm{t}}}{\pi \mathrm{r}^{2}}\right) \mathrm{dS}
$$

where $W_{t}$ is the total acoustic power radiation from the power park of area $\pi r^{2}$. The radius of the $75 \mathrm{sq}$. mile power park is

$$
\mathrm{C}=25,800 \mathrm{ft} \text {. }
$$




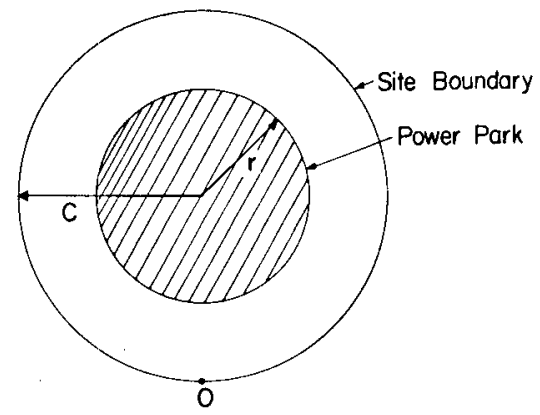

Figure 6. Overall configuration of the site containing $48,000 \mathrm{MW}$ of power generation.

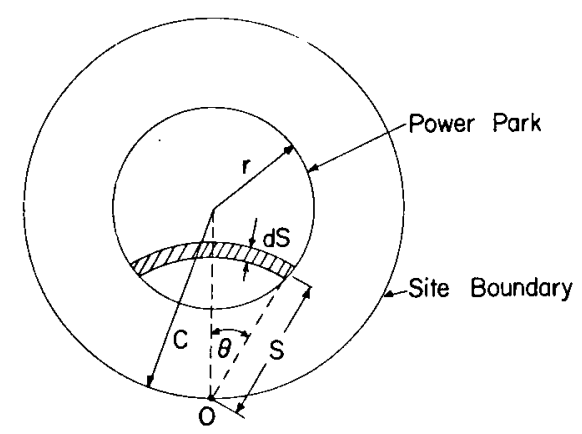

Figure 7. Geometrical configuration of site for the purpose of problem analysis. 
and, for purposes of later integration, we record the geometrical relation

$$
\theta=\tan ^{-1} \frac{\sqrt{4 c^{2} s^{2}-\left(s^{2}-r^{2}-c^{2}\right)^{2}}}{s^{2}-r^{2}+c^{2}}
$$

\subsection{Natura1-Draft Wet Towers}

The acoustic power resulting in the A-weighted SPL, for one wet tower of Figure 1, was found in Section 2.1 to be 1.474 Watts. For $48 \mathrm{GW}$, it will be 80 times as great, or $\mathrm{W}_{t}=117.92$ Watts. It was shown in Section 2.1 that for $S>>R$, Eq. (4), derived on the basis of uniform hemispherical spreading, reduces to:

$$
\mathrm{P}_{\mathrm{A}}^{2}=\frac{\mathrm{W}_{\mathrm{ac}} \mathrm{Z}_{\mathrm{o}}}{4 \pi \mathrm{s}^{2}}
$$

where $Z_{0}$, as stated earlier, is the atmospheric impedance. It will be seen later in this section that distances $S$ involved in the analysis will be great as compared to $R$. Therefore, more conveniently, we shall use

Eq. (5) instead of Eq. (4) for the present power park case.

For any area element of Figure 7, Eqs. (15) and (5) give

$$
\mathrm{P}_{\mathrm{A}}^{2}=\frac{117.92 \mathrm{z}_{\mathrm{o}} \theta(\mathrm{dS})}{2 \pi^{2} \mathrm{r}^{2} \mathrm{~S}}
$$

where $\mathrm{r}$ and $\mathrm{S}$ are in meters, and $\theta$ is given by $\mathrm{Eq} .(16)$.

The A-weighted SPL at a distance $S$ from any element area source is then found by using Eq, (18) in Eq. (3):

$$
\mathrm{SPL}_{\mathrm{S}}=10 \log _{10}\left\{\frac{58.96 \mathrm{z}_{\mathrm{o}} \theta(\mathrm{dS})}{\pi^{2} \mathrm{r}^{2} \mathrm{~S}\left(2 \cdot 10^{-5}\right)^{2}}\right\} \text { DBA re } 2 \cdot 10^{-5} \mathrm{~N} / \mathrm{m}^{2}
$$

Note that Eq. (19) is analogous to Eq. (7) developed for single isolated towers. Following the steps of Section 2.1 for a center frequency of, 
for example, 8,000 $\mathrm{Hz}$, Eq. (19) and Tables 1 and 3 yield the following equation for the A-weighted SPL with atmospheric attenuation:

$$
\mathrm{SPL}_{\mathrm{a}}=10 \log _{10}\left\{\frac{58.96 \mathrm{z}_{\mathrm{o}} \theta(\mathrm{dS})}{\pi^{2} \mathrm{r}^{2} \mathrm{~S}\left(2 \cdot 10^{-5}\right)^{2}}\right\}-7.2-\frac{\mathrm{S} \times 14.4}{300} \text { DBA re } 2 \cdot 10^{-5} \mathrm{~N} / \mathrm{m}^{2}
$$

Writing Eq.(20) in a different form:

$$
\begin{aligned}
& \mathrm{SPL}_{\mathrm{a}}(\text { for } 8 \mathrm{KHz})=10 \log _{10}\left\{\frac{58.96 \mathrm{Z}_{\mathrm{o}} \theta(\mathrm{dS})}{\pi^{2} \mathrm{r}^{2} \mathrm{~S} 10^{(14.4 \mathrm{~S} / 3000)+.72]}\left(2 \cdot 10^{-5}\right)^{2}}\right\} \\
& \quad \mathrm{DBA} \text { re } 2 \cdot 10^{-5} \mathrm{~N} / \mathrm{m}^{2}
\end{aligned}
$$

From Eqs.(7) and (21), the intensity of sound for a center frequency of $8 \mathrm{KHz}$ reaching the point 0 , at a distance $\mathrm{S} \mathrm{m}$. from the area strip of Figure 7, will be:

$$
\mathrm{I}=\frac{\mathrm{P}_{\mathrm{A}}^{2}}{\mathrm{Z}_{\mathrm{o}}}=\frac{58.96 \theta(\mathrm{dS})}{\pi^{2} \mathrm{r}^{2} \mathrm{~S}(10[(14.4 \mathrm{~S} / 3000)+.72])} \text { Watts }
$$

For any $\mathrm{r}$, and $\mathrm{C}$ being constant $(=25,800 \mathrm{ft}), \mathrm{Eq} .(22)$ can be integrated over the area $\pi r^{2}$ to give the total sound intensity at the point 0 for $8 \mathrm{Khz}$.

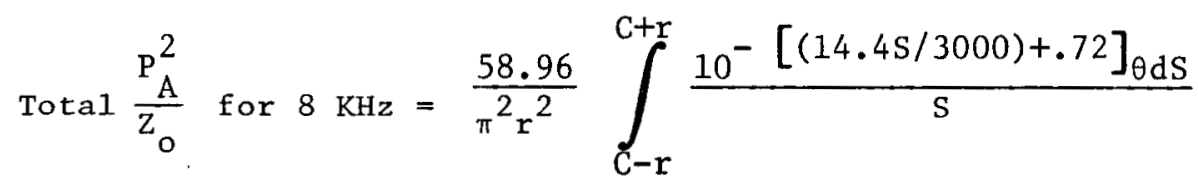

In this way intensities for all center frequencies in the spectrum can be found and the total sound level can then be computed by summing all such sound intensities as given by Eq. (23):

$\operatorname{Total} \frac{\mathrm{P}_{\mathrm{A}}^{2}}{Z_{\mathrm{o}}}$ for the whole spectrum $=$ 


$$
\begin{aligned}
& \frac{58.96}{\pi^{2} r^{2}} \int_{C-r}^{C+r}\left\{10^{-1.94}+10^{-[(.014 S / 3000)+1.98]}+10^{-[(.7 S / 3000)+1.3]}\right. \\
& +10^{-[(1.4 S / 3000)+.78]}+10^{-[(3 S / 3000)+.63]+10^{-}[(7.7 \mathrm{~S} / 3000)+.43]} \\
& +10^{-[(14.4 \mathrm{~S} / 3000)+.72]}\left(\frac{\theta}{S}\right) \mathrm{dS}
\end{aligned}
$$

Net DBA's reaching at the point 0 for the some value of $r$ are then calculated by using Eqs. (7) and (24):

$$
\mathrm{SPL}_{\mathrm{a}}=10 \log _{10}\left\{\frac{\mathrm{P}_{\mathrm{A}}^{2} \text { (from eq. (3.8)) }}{\left(2 \cdot 10^{-5}\right)^{2}}\right\} \text { DBA re } 2 \cdot 10^{-5} \mathrm{~N} / \mathrm{m}^{2}
$$

The integral of Eq. (24) was evaluated by the help of the computer by taking $d S=45 \mathrm{ft}$. The results are plotted in Figure 3 for $r$ ranging from $6,000 \mathrm{ft}$ to $25,000 \mathrm{ft}$.

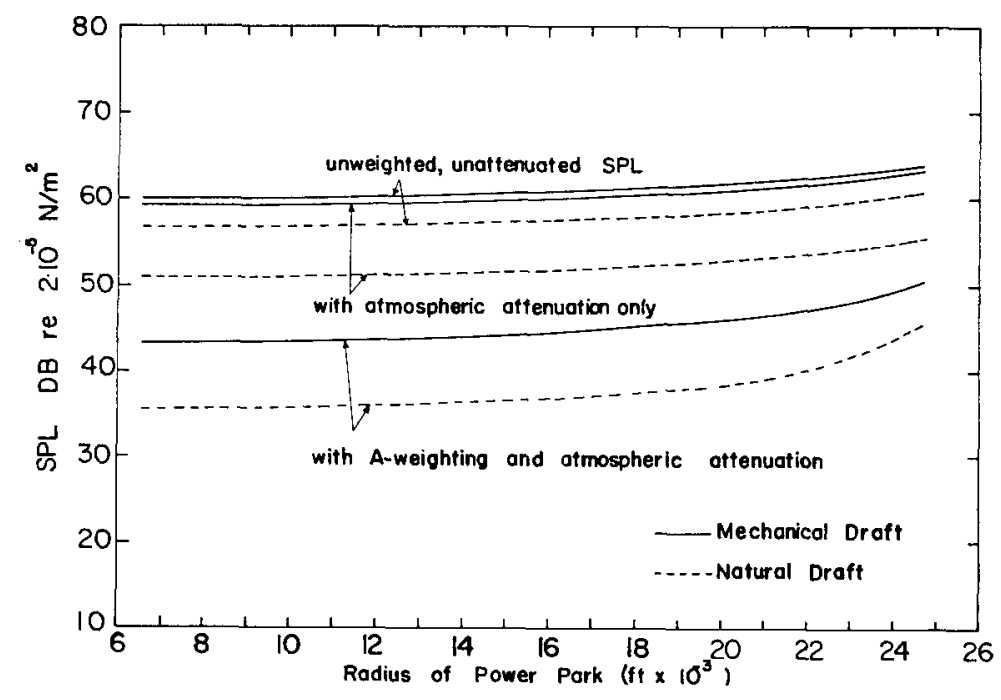

Figure 8. Variation of sound pressure levels at the site boundary with Radius of Power Park. 


\subsection{Mechanical-Draft Wet Towers}

Using a 3 PPM efficiency of rated fan power for conversion into acoustic power (see Section 2.2), the total acoustic power generation from the area of the $48 \mathrm{GW}$ energy center will be 80 times of that from a $600 \mathrm{MW}$ power plant. The SPL at a distance $\mathrm{S}$ from any element area source, for an assumed uniform spherical spreading, can be found from Eq. (12) :

$$
\mathrm{SPL}_{\mathrm{S}}=10 \log _{10}\left\{\frac{10^{10.5}(\mathrm{dhp})}{4 \pi \mathrm{S}^{2}}\right\} \text { DB re } 10^{-13} \text { watts }
$$

where $\mathrm{S}$ is in feet, and $\mathrm{dhp}$ is the rated fan horsepower existing within the area element being considered. Also,

$$
\mathrm{dhp}=\frac{3625 \times 80}{\pi \mathrm{r}^{2}} \quad 2 \mathrm{~S} \theta(\mathrm{dS})
$$

where units of $\mathrm{r}$ and $\mathrm{S}$ should be the same. The rest of the procedure for the prediction of SPL at 0 is the same as presented in Section 3.1. In this case, however, an additional A-weighting reduction is required in each frequency band. The data to be used is presented in Section 2.2. The results for $\mathrm{r}$ ranging from $6,000 \mathrm{ft}$ to $25,000 \mathrm{ft}$, are plotted in Figure 8 along with those for natural-draft towers for comparison.

\subsection{Discussion}

Figure 8 shows that mechanica1-draft tower noise is nearly constant over the range of $r$ considered. While natural-draft tower noise has initially a shallow slope with $r$, it increases more rapidly with greater $r$ than does the mechanical-draft tower noise. Considering the naturaldraft towers first, we notice that noise level at the site boundary increases significantly beyond an $\mathrm{r}$ of about 10,000 ft, or as the shortest distance from the periphery of the area source to the point 0 decreases. This happens because at large radii, (C-r) is small, and sound energies emanating from the far side of the park are relatively ineffective; thus the major effect is due to the nearer area elements. 
But as $\mathrm{r}$ is decreased, ( $\mathrm{C}-\mathrm{r}$ ) increases and the effect of dispersed sources becomes insignificant and the area source behaves more like a point source. This results in an almost constant noise level of about 35 DBA for $r$ less than $8,000 \mathrm{ft}$.

For mechanical-draft tower systems the atmospheric absorption is negligible, A-weighting rejects about $16 \mathrm{DB}$ 's and is the major reason why actual sound levels are considerably lower than the unweighted, unattenuated levels (Figure 6). The impact of scattered sources, as is the case of natural-draft towers, becomes insignificant at smaller $r$, resulting in about a constant SPL of 43 DBA.

Fina1ly, we should indicate briefly the possible range of park radii for which sound levels at the site boundary (Figure 6) would not exceed $45 \mathrm{DBA}^{*}$. For mechanical-draft tower systems this level will be reached at a park radius of $17,500 \mathrm{ft}$. This radius will be about $24,500 \mathrm{ft}$ for natural-draft towers.

\footnotetext{
* See Section 2.3 .
} 


\section{Chapter 4}

COOLING TOWER NOISE WITHIN THE ENERGY CENTER

In the two previous chapters we analyzed the noise radiation from a single isolated tower, and that from an energy center as measured at a point beyond its boundary. Thus no attention was paid to the SPL existing within the energy center shown shaded in Figure 6 . If, however, the restriction of the site boundary is removed and the towers are more widely dispersed, then it will be interesting to know the noise levels within the area over which the towers are spread. We shall, therefore, now investigate the generation of noise from the cooling towers of a dispersed array of $600 \mathrm{MW}$ power stations. Whereas in Chapter 3 the listener was outside the concentrated power plant system, in this chapter the listener is placed among and surrounded by power plants, which themselves are much farther apart, or dispersed, than in the previous case. In this analysis we shall consider that the array of towers may extend indefinitely around a point where we sha11 be interested in finding the total noise impact. Each of the towers considered will be a typical tower for a $600 \mathrm{MW}$ station described in Chapter 2.

\subsection{Geometrical Configuration of Array of Towers}

In this section we shall present the analysis when the location of the dispersed towers has been approximated by the mesh points of a square grid. Considerable emphasis has been placed upon the grid size (degree of dispersion), the area over which the towers are spread, and their effect on noise levels at the observing point.

The mesh points of the square grid mentioned above are shown in Figure 9. Point 0 is located at the center of the innermost square and will be our point of interest where we would like to know the SPL due to the surrounding towers. It should be noted that the cooling tower array may extend indefinitely on all sides of the point 0 . For the 


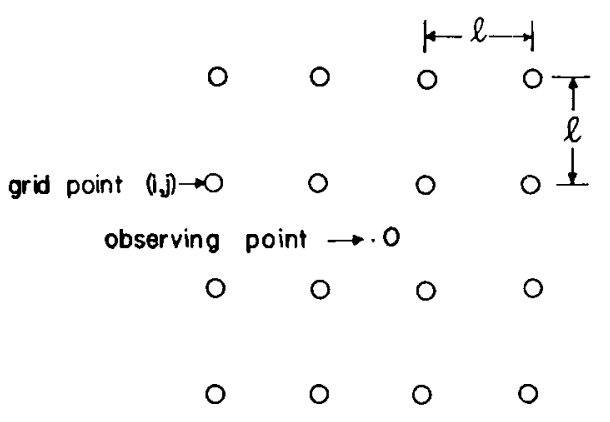

Figure 9. Grid points for a square mesh work, representing the location of the array of dispersed towers as the sources of noise generation. The dimension $\ell$ is the distance between the center points of towers as shown.

geometrical analysis we designate each of the grid points as $(i, j)$, where $i$ is the number assigned to each square with the point 0 on its center. The innermost square being $i=1$. The next bigger $i=2$, and so on (note that in Figure 9 only the squares $\mathbf{i}=1$ and 2 are shown), $j$ is the number given to the grid points located on the i-th square. For the top left corner grid point we will have $j=1$, and then $j$ increases as we move along the grid points on the $i-t h$ square in the clockwise direction. In fact, due to symmetry, we would be interested only in the first $i$ number of grid points for the i-th square (Figure 10).

The distance $S(i, j)$ from the rim of a natural-draft tower located at the point $(i, j)$ to the point 0 will be given by the following formula:

$$
S(i, j)=\frac{\ell(i-0.5)}{\cos [\theta(i, j)]}-R
$$

where $\theta(i, j)=(i-j+0.5) /(i-0.5)$

Now we shall assume that a mechanical-draft tower will be spread over the same ground area if substituted for a natural-draft tower, and hence $S(i, j)$ 


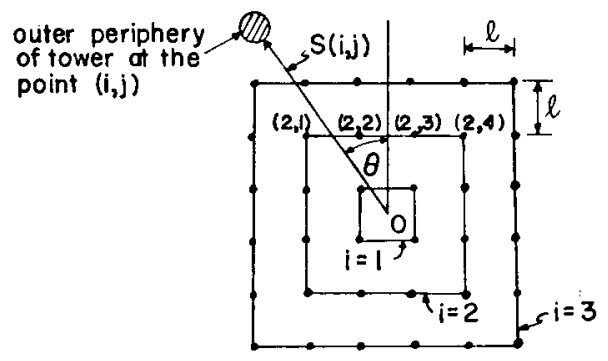

Figure 10. Geometrical configuration of the extending array of towers. For this figure the value of $n$ will be 3 .

for mechanical-draft towers will also be given by $\mathrm{Eq.} \mathrm{(28).}$

\subsection{Estimation of Noise Leve1s at the Point 0}

We shall consider the dispersed array of natural- and mechanical-draft towers separately and then present the results together in a graphical form. Noise levels at the point 0 will be calculated for the following conditions :

1) Increasing $n$, i.e. $n=1,2,3 \ldots \ldots$, while keeping $\ell$ fixed.

2) Increasing $\ell$ and repeating the procedure with increasing values of $n$.

Natural-Draft Tower Array: Corresponding to Eq. (4), here we shall use the following equation for the A-weighted root mean square sound pressure emitted by a natural-draft tower located at the grid point $(i, j)$ of Figure 10:

$$
P_{A}^{2}(i, j)=\frac{w_{a c} Z_{o}}{\pi^{2}\left(S^{2}(i, j)+2 S(i, j) R\right)} \tan ^{-1} \sqrt{\frac{S(i, j)+2 R}{S(i, j)}}
$$

where $S(i, j)$ for the point $(i, j)$ is obtained from Eq, (28). We also know by the definition of SPL that: 


$$
\operatorname{SPL}(i, j)=10 \log _{10}\left\{\frac{P_{A}^{2}(i, j)}{\left(2 \cdot 10^{-5}\right)^{2}}\right\} \quad \text { DBA re } 2 \cdot 10^{-5} \mathrm{~N} / \mathrm{m}^{2}
$$

In order to apply atmospheric attenuation to a particular $\operatorname{SPL}(i, j)$ given by Eq. (30), we must first find the SPL's for the individual center frequencies in the noise spectrum. And then following the procedure described in Section 2.1 we can compute the DBA's with atmospheric attenuation at the point 0 due to the tower at $(i, j)$. Finally, the noise level at the point 0 due to the array as a whole can be found as follows:

$$
\operatorname{SPL}(0)=10 \log _{10}\left\{4 \sum_{i=1}^{\mathrm{n}} \sum_{j=1}^{2 i-1}\left[10^{.1} \mathrm{SPL}_{a}(i, j)\right]\right\} \text { DBA re } 2 \cdot 10^{-5} \mathrm{~N} / \mathrm{m}^{2}
$$

The term within the brackets of eq. (31) is simply a sum of the sound intensities, due to $4 \sum_{\mathbf{i}=1}^{\mathrm{n}}(2 \mathbf{i}-1)$ towers constituting the array of towers under study, divided by the reference sound pressure of $2 \cdot 10^{-5} \mathrm{~N} / \mathrm{m}^{2}$. The subscript a, refers to the atmospheric attenuation as stated earlier in Example 2.1.

Eq. (31) was evaluated by the help of the computer. For each $\ell$, $\mathrm{n}$ was taken up to 20 although the impact of $\mathrm{n}$ higher than about 7 is relatively insignificant in terms of SPL( 0$)$. The results are presented in Figure 11 for $\ell$ ranging from 600 to 15,000 ft. Figure 12 shows theoretically predicted SPL at the point 0 for the two types of dispersed tower sources with increasing $\ell$.

Mechanica1-Draft Tower Array: Corresponding to Eqs. (10) and (11) of Section 2.2, we shall have the following equations for a mechanicaldraft tower located at the grid point $(i, j)$ of Figure 10:

$$
\begin{aligned}
& I_{\omega}(i, j)=105+10 \log _{10}(h p) \text { DB re } 10^{-13} \text { Watts } \\
& \operatorname{SPL}(i, j)=I_{\omega}(i, j)-10 \log _{10}\left[4 \pi s^{2}(i, j)\right] \text { DB re } 10^{-13} \text { Watts }
\end{aligned}
$$




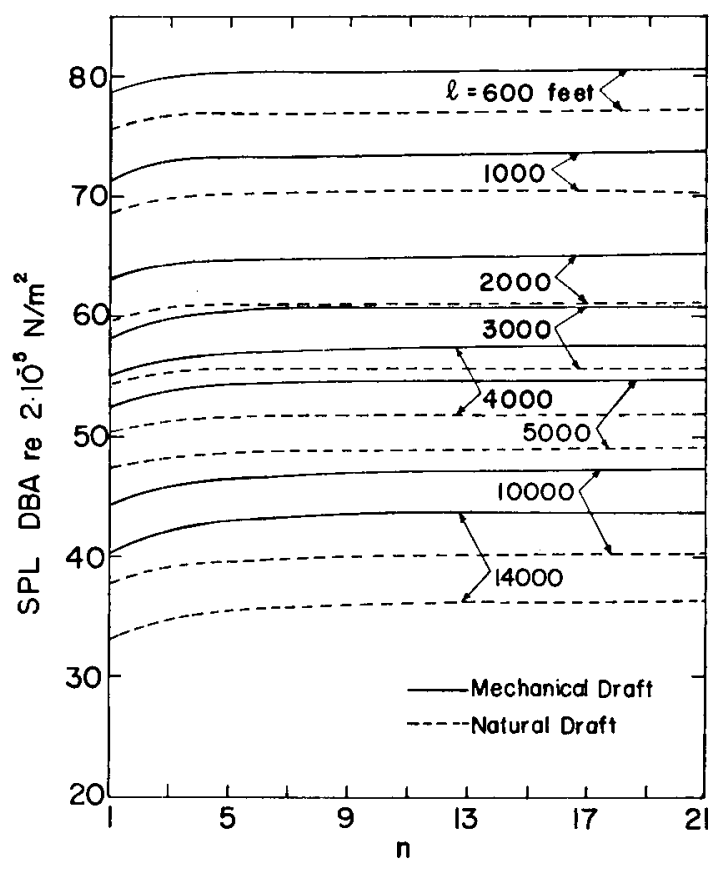

Figure 11. Sound levels at the point O (Figure 10) due to a dispersed array of natural- and mechanicaldraft tower sources. A description of a typical tower for a $600 \mathrm{MW}$ electric generating station is presented in Sections 2.1 and 2.2 .

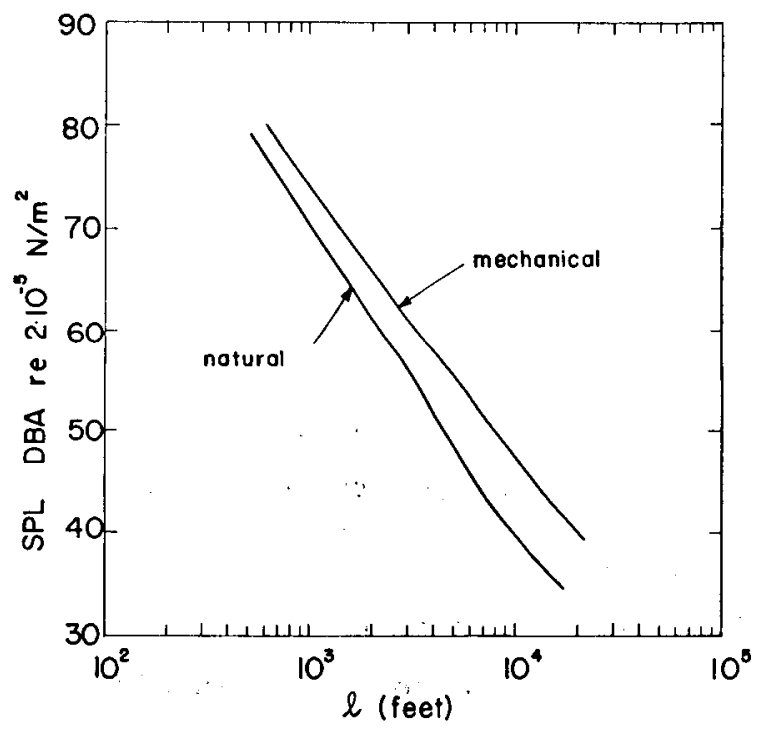

Figure 12. Change of noise levels at the point 0 with $\ell$ for the configuration of the dispersed tower sources of Figure $10, \mathrm{n}=15$. 
Knowing SPL $(i, j)$ from Eq. (33) we can calculate $\operatorname{SPL}_{a}(i, j)$ by the method illustrated in Example 2.2. Eq. (31) can then be used for the prediction of SPL(0). The results are presented in Figures 11 and 12 along with those for natural-draft towers for comparison.

\subsection{Noise Level Contour}

The next step in this chapter will be to find the distribution of SPL's within the area of the mesh of grid points. It should be noted that if the point 0 is displaced from its central position then the problem no longer remains symmetrical and extra computation is required to find $S(i, j)$. To make the problem simpler we consider only the innermost square (i.e., $i=1$ ), and calculate the net SPL at various subgrid points within this square, Figure 14. Then applying a correction for the SPL at each sub-grid point, we can account for the situation if the mesh were indefinitely extended. We can easily deduce an estimate of such a correction by observing Figure 11, which shows that as $n$ increases from $\mathrm{n}=1$, there is only a small difference of noise levels, and that the levels become sufficiently constant beyond $n=13$. Thus by keeping $\mathrm{n}=1$, noise levels at any point within this square can be calculated by hand methods and the small increase of levels, as depicted by Figure 11, can then be added to our results for each sub-grid point to account for large $n$. We are assuming, of course, that these corrections will be the same throughout the area under consideration, for a particular $\ell$. These corrections, which we shall call $\Delta$, were computed numerically and are presented in graphical form in Figure 13. We do not intend to present an analytical expression for $\Delta$ because the algebra involved becomes very tedious. Section 4.4 and the Appendix explain the behavior of $\Delta$ with the degree of dispersion of towers.

It should be emphasized that in the construction of Figure 13, the atmospheric absorption effect of that part of the noise spectrum 1ying below $200 \mathrm{~Hz}$ was also taken into account. This additional atmospheric absorption at very low frequencies, however, will have a negligible effect on the curves of Figure 13 for $\ell$ below of about 30,000 ft. 


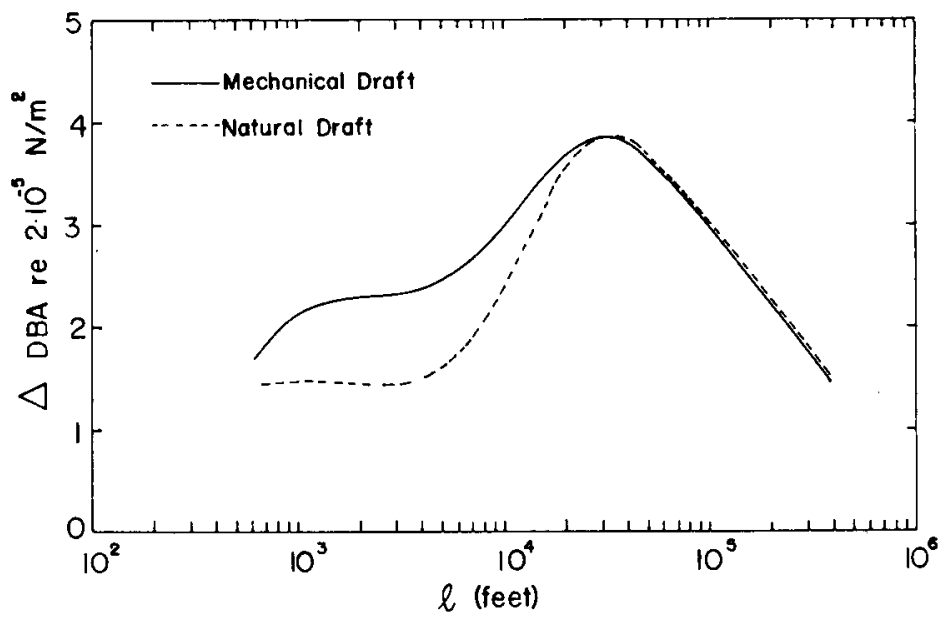

Figure 13. The value of $\Delta$ with increasing $\ell$, $\mathbf{n}$ being fixed at 15. The configuration is that of Figure 10 for the dispersed array of natural- and mechanicaldraft towers acting as sources of acoustic power.

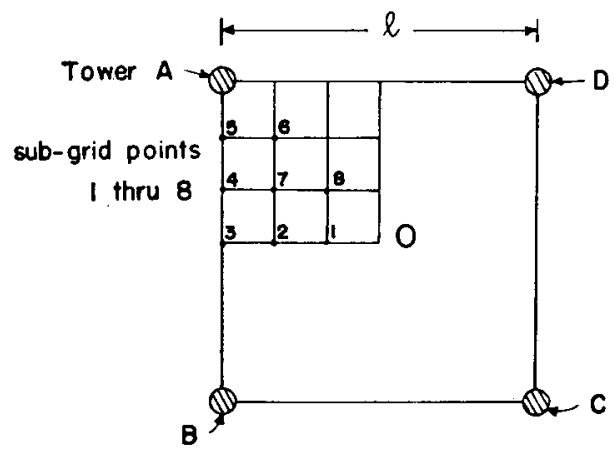

Figure 14. Location of the sub-grid points. 
Example 4.3:

Consider, as an example, the dispersed array of natural-draft towers, each tower being that of Figure 1 . We shall attempt to compute the noise level contour for the case when $l=4,000 \mathrm{ft}$. The correction to be applied at each of the sub-grid points will be 1.5 DBA from Figure 13. Due to symmetry only 8 sub-grid points shown in Figure 14 need be considered. Figure 15 presents the noise levels at the points 1 thru 8, due to each of the towers A, B, C and D if considered separately. The overall sound levels, including the correction of $+1.5 \mathrm{DBA}$, are stated within the parenthesis for each of the eight sub-grid points. Finally, a sketch of the SPL contour, extrapolated from the data presented in Figure 15, is shown in Figure 16.

\subsection{Simplified Geometrical Approximation for the Dispersed Array of Towers}

We shall now make another approximation for the location of the randomly spread towers, and consider a simpler geometry, where the towers will be located on the circumference of concentric circles of radii which are integer multiples of some number (Figure 17). This approximation, being simpler, helps to explain the variation of $\Delta$ with system dimensions, as compared to the square grid approximation of Section 4.1.

Consider that the towers are located on the circumference of concentric circles of radii $i$ times some value, say $L$, where $i=1,2, \ldots n$. Consider also that on the circumference of the circle of radius $\mathrm{L} x \mathrm{i}$, we place $4(2 i-1)$ towers. It should be noted that under the present circumstances we are simply replacing the $i-t h$ square of Figure 10 with i-th circle, having on its circumference the same number of towers as on the $i-t h$ square of the previous geometry. We would now be interested in finding the increase of sound levels at the center $0^{\prime}$, Figure 17, when $\mathrm{n}$ is increased from 1 to some higher number. It is worth mentioning at this point that having introduced the circles instead of squares we have considerably simplified the geometry of the configuration because now all the towers on the $i-\underline{t h}$ square will be equidistant from the central point $0^{\prime}$. 


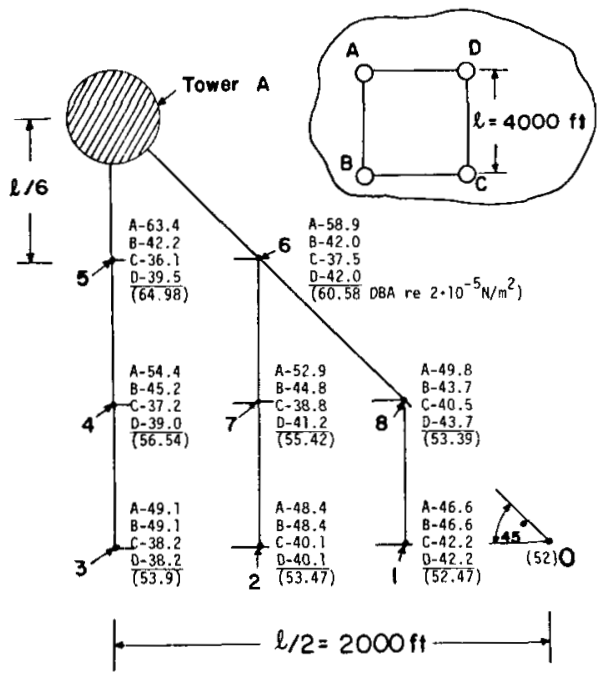

Figure 15. Noise level contour computation scheme. The numbers in parenthesis include the correction of $+1.5 \mathrm{DBA}$ for $\ell=4,000 \mathrm{ft}, \mathrm{n}=15$.

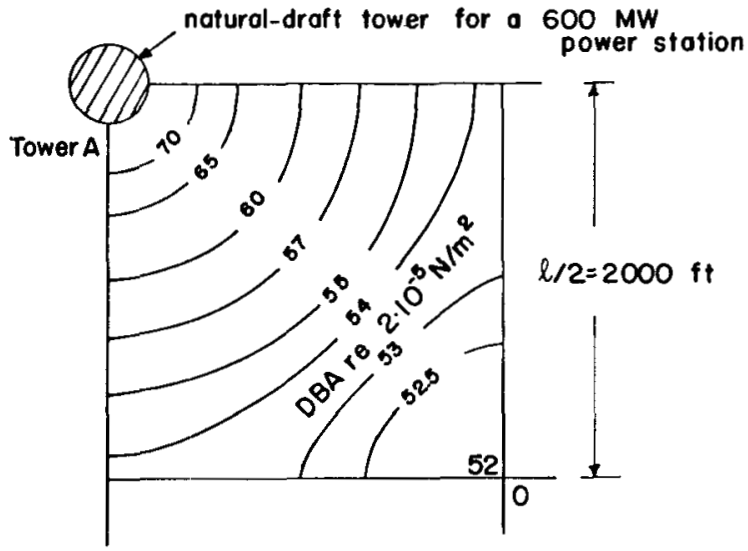

Figure 16. Theoretically predicted noise leve1 contours associated with a dispersed array of naturaldraft towers. A schematic of a typical tower for a $600 \mathrm{MW}$ power station is shown in Figure 1. For the geometry of the distribution of tower sources see Figures 9 and $10, \mathrm{n}=15$. 


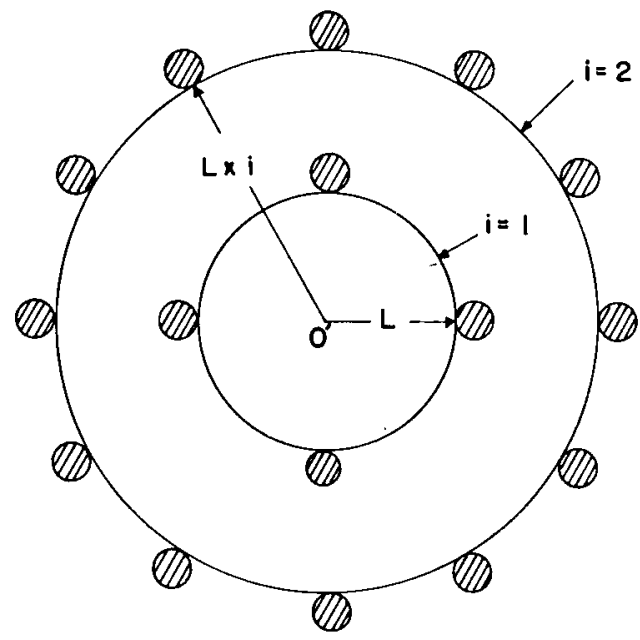

Figure 17. Alternative geometrical configuration for the dispersed array of towers. Note that the total number of towers located on the ith circle will be $4(2 i-1)$. L $x i$ is the shortest distance from the observing point $O^{\prime}$ to the rim of the tower associated with the ith circle.

Natural-Draft Tower Array: Considering natural-draft towers first, we recall Eq. (30) which for single towers can be written as:

$$
\mathrm{SPL}_{\mathrm{S}}=10 \log _{10}\left\{\frac{\mathrm{P}_{\mathrm{A}}^{2}}{\left(2 \cdot 10^{-5}\right)^{2}}\right\} \text { DBA re } 2 \cdot 10^{-5} \mathrm{~N} / \mathrm{m}^{2}
$$

and similarly SPL in each frequency band can be found by the following equation:

$$
\mathrm{SPL}_{\mathrm{p}}=10 \log _{10}\left\{\frac{\mathrm{P}_{\mathrm{A}}^{2}}{\left(2 \cdot 10^{-5}\right)^{2}}\right\}-\mathrm{A}_{\mathrm{p}} \text { DBA re } 2 \cdot 10^{-5} \mathrm{~N} / \mathrm{m}^{2}
$$

where $\mathrm{SPL}_{p}$ is the SPL in the $\mathrm{p}-\underline{\mathrm{th}}$ frequency band, and $\mathrm{A}_{\mathrm{p}}$ 's are the relative reduction of levels for each band.

Taking atmospheric attenuation into account, Eq. (35) can be further modified as:

$$
S P L_{p}=10 \log _{10}\left\{\frac{\mathrm{P}_{A}^{2}}{\left(2 \cdot 10^{-5}\right)^{2}}\right\}-A_{p}-\frac{L}{300} \quad T_{p} \quad \text { DBA re } 2 \cdot 10^{-5} \mathrm{~N} / \mathrm{m}^{2}
$$


where $\mathrm{L}$ is in meters and $\mathrm{T}_{\mathrm{p}}$ is the atmospheric absorption in DB re $2 \cdot 10^{-5}$ $\mathrm{N} / \mathrm{m}^{2} / 300 \mathrm{~m}$ in the $\mathrm{p}-\mathrm{th}$ frequency band. $\mathrm{A}_{\mathrm{p}}$ and $\mathrm{T}_{\mathrm{p}}$ are stated in Table 9. We can now write Eq. (36) in the following form:

$$
\mathrm{SPL}_{\mathrm{p}}=10 \log _{10}\left\{\frac{\mathrm{P}_{\mathrm{A}}^{2}}{\left(2 \cdot 10^{-5}\right)^{2} 10^{.1 \mathrm{~A}_{\mathrm{p}_{10}} \mathrm{bT}_{\mathrm{p}}^{\mathrm{L}}}}\right\} \text { DBA re } 2 \cdot 10^{-5} \mathrm{~N} / \mathrm{m}^{2}
$$

where $\mathrm{b}=$ constant $=1 / 3,000$.

\section{Table 9}

Spectrum, Atmospheric Attenuation, and A-Weighting Data

$$
\begin{aligned}
& A_{p}=\text { Spectral reduction in } \mathrm{DB} \\
& T_{p}=\text { Atmospheric absorption in } \mathrm{DB} / 984 \mathrm{ft} \\
& W_{p}=\text { A-weighting reduction in } \mathrm{DB}
\end{aligned}
$$

\section{Natura1-Draft Towers}

\begin{tabular}{ccc}
$\begin{array}{c}\text { Band } \\
\mathrm{p}\end{array}$ & $\mathrm{A}_{\mathrm{p}}$ & $\mathrm{T}_{\mathrm{p}}$ \\
\hline 1 & $\frac{19.4}{.0049}$ & $\frac{.014}{2}$ \\
2 & 19.8 & .7 \\
3 & 13.0 & 1.4 \\
4 & 7.8 & 3.0 \\
5 & 6.3 & 7.7 \\
6 & 4.3 & 14.4 \\
7 & 7.2 &
\end{tabular}

Mechanica1-Draft Towers

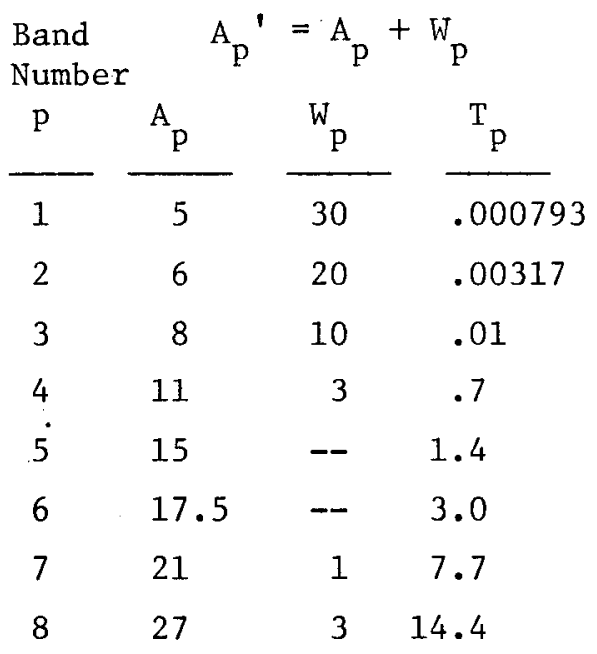

It should be mentioned that although we used the values of $A_{p}$ and $T_{p}$ in Chapters 2 and 3 , we did not introduce these symbols (i.e. $A_{p}, T_{p}$, etc.). In this chapter, however, we shall frequently refer to these symbols instead of their numerical values to simplify the mathematical expressions. 
We can now recover the total SPL whick actually reaches a point located at a distance L from the source by using Eq. (37).

$$
\mathrm{SPL}_{\ell}=10 \log _{10}\left\{\sum_{\mathrm{p}=1}^{\mathrm{k}}\left[\frac{\mathrm{P}_{\mathrm{A}}^{2}}{\left(2 \cdot 10^{-5}\right)^{2} 10^{\cdot 1 \mathrm{~A}} \mathrm{p}_{10}{ }^{\mathrm{bT}} \mathrm{p}}\right]\right\}_{\mathrm{DBA}}^{\mathrm{L}} \mathrm{\text {re }} 2 \cdot 10^{-5} \mathrm{~N} / \mathrm{m}^{2}
$$

Since we are considering 7 frequency bands for natural-draft tower noise, $k$ will be 7 for such towers.

We can now use Eq. (38) for the array of towers presently under consideration, and because $4(2 i-1)$ towers are located on the $i$-th circle of radius $L \times i$, the SPL at the central point $0^{\prime}$ due to the array on the i-th circle will be:

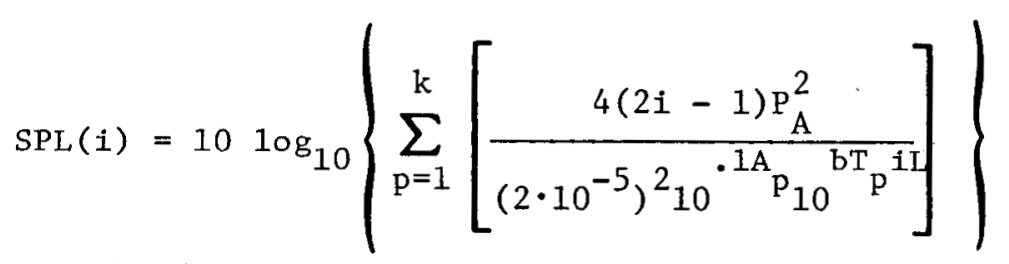

The A-weighted root mean square sound pressure, $P_{A}$, in $E q$. (39) is given by Eq. (29), which, for $L$ large compared to $R$, reduces to the following equation for a natural-draft tower located on the i-th circle of Figure 17:

$$
\mathrm{P}_{\mathrm{A}}^{2}=\frac{\mathrm{W}_{\mathrm{ac}} \mathrm{Z} o}{\pi^{2} i^{2} L^{2}}\left(\frac{\pi}{4}\right)
$$

Eqs. (39) and (40) can be combined to give

$$
\begin{aligned}
& \text { SPL(i) }=10 \log _{10}\left\{\sum_{\mathrm{p}=1}^{k}\left[\frac{(2 i-1) \mathrm{w}_{a c} z_{o}}{\pi^{2} i^{2} L^{2}\left(2 \cdot 10^{-5}\right)^{2} 10^{\cdot 1 A_{p_{10}}{ }^{b T} \mathrm{iL}}}\right]\right\}
\end{aligned}
$$

or

$$
\operatorname{SPL}(i)=10 \log _{10}\left\{\sum_{\mathrm{p}=1}^{k}\left[\frac{\mathrm{B}(2 \mathrm{i}-1)}{\mathrm{i}^{2} \mathrm{~L}^{2} 10^{\cdot 1 \mathrm{p}_{10} \text { bT } \mathrm{pL}}}\right]\right\}
$$

where

$$
B=\text { constant }=\frac{W_{a c} Z_{o}}{\pi\left(2 \cdot 10^{-5}\right)^{2}}
$$


For $n$ circles, i.e. $i=1,2, \ldots n$, the total SPL at $0^{\prime}, \operatorname{SPL}\left(0^{\prime}\right)$, can be easily computed by the help of Eq. (41):

$$
\operatorname{SPL}\left(0^{\prime}\right)=10 \log _{10}\left\{\sum_{i=1}^{n}\left[\sum_{p=1}^{k}\left(\frac{B(2 i-1)}{i^{2} L^{2} 10^{.1 A_{p}{ }^{b T} p^{i I}}}\right)\right] \text { DBA re } 2 \cdot 10^{-5} \mathrm{~N}^{2} \mathrm{~m}^{2}\right.
$$

The difference $\Delta$, of the SPL experienced at $0^{\prime}$ when $n=1$ and when $n=n$ will be

$$
\begin{aligned}
& \Delta=10 \log _{10}\left\{\sum_{i=1}^{n}\left[\sum_{p=1}^{k}\left(\frac{B(2 i-1)}{i^{2} L^{2} 10^{.1 A_{10} p_{10} i t}}\right)\right]\right. \\
& -10 \log _{10}\left\{\sum_{\mathrm{p}=1}^{\mathrm{k}}\left(\frac{\mathrm{B}}{\mathrm{L}^{2} 10^{.1 \mathrm{~A}_{10} \mathrm{bT} \mathrm{L}}}\right)\right\}
\end{aligned}
$$

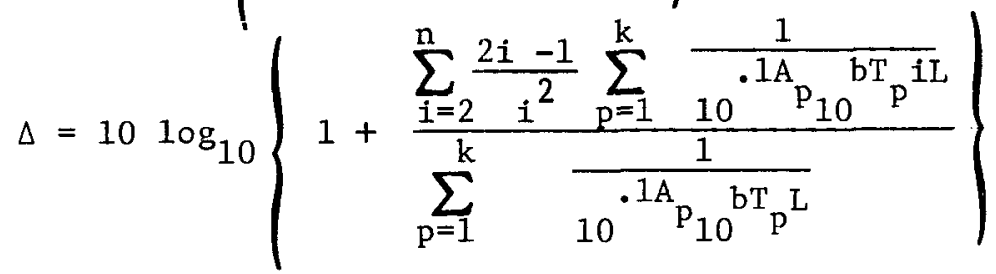

or

Identifying the second term in brackets as $\Pi$,

$$
\Pi \equiv \frac{\sum_{i=2}^{n} \frac{2 i-1}{i^{2}} \sum_{p=1}^{k} 10^{-0.1 A_{p}-b T_{p} i L}}{\sum_{p=1}^{k} 10^{-0.1 A_{p}-b T_{p}^{L}}}
$$

It is obvious that

$$
\Pi=\Pi(n, L)
$$

since $A_{p}$ and $T_{p}$ are constants. We may note that if $n=1$, then $I=0$ and Eq. (43) gives $\Delta=0$.

Eq. (43) is perhaps the most comprehensive form for $\Delta$ without making drastic simplifications. We shall therefore stop at this point in this section. However, a further "discussion of the form of $\Delta$ " is given in the Appendix. 
Mechanica1-Draft Tower Array: For mechanical-draft towers we first combine Eqs. (32) and (33) to get

$$
\mathrm{SPL}_{\mathrm{S}}=10 \log _{10}\left\{\frac{10^{10.5} \mathrm{hp}}{4 \pi \mathrm{L}^{2}}\right\} \mathrm{DB} \text { re } 10^{-13} \text { Watts }
$$

where L is in feet. Corresponding to Eq. (35) for natural-draft towers, we shall have the following equation for mechanical-draft systems:

$$
\mathrm{SPL}_{\mathrm{p}}=10 \log _{10}\left\{\frac{10^{10.5} \mathrm{hp}_{\mathrm{p}}}{4 \pi \mathrm{L}^{2}}\right\}-\mathrm{A}_{\mathrm{p}}^{\prime}-\frac{\mathrm{LT}}{984} \quad \mathrm{DBA} \text { re } 2 \cdot 10^{-5} \mathrm{~N} / \mathrm{m}^{2}
$$

where $A_{p}^{\prime}=A_{p}+W_{p} ; W_{p}$ being the additional $D B$ redustion required for the A-weighting. $A_{p}$ and $W_{p}$ are given on Table 8 . Proceeding onwards from Eq.(46), one obtains, finally;

$$
\operatorname{SPL}\left(0^{\prime}\right)=10 \log _{10}\left\{\sum_{i=1}^{n}\left[\sum_{p=1}^{k}\left(\frac{B^{\prime}(2 i-1)}{\left.{ }^{2} L^{2} 10^{\circ}{ }^{1 A_{p}^{\prime} 10^{b T} \mathrm{PT}_{\mathrm{p}} \mathrm{L}}\right)}\right)\right] \text { DBA re } 2 \cdot 10^{-5} \mathrm{~N} / \mathrm{m}^{2}\right.
$$

where

$$
\mathrm{B}^{\prime}=\frac{10^{10 \cdot 5} \mathrm{hp}}{\pi}
$$

and $K=8$ for mechanical-draft towers, and since the units of $L$ are in feet, the constant $\mathrm{b}$ will be $1 / 9,840$. The expressions for $\Delta$ and $\pi$ will be the same as Eqs. (43) and (44), respectively, except that $A_{p}$ is to be replaced by $A_{p}^{\prime} \cdot$

Fina11y, for this geometrical configuration, Figures 18, 19, and 20 are presented for comparison with Figures 11, 12 and 13 for the geometry of Section 4.1.

We now show an example in which we compare the predicted sound levels for the geometrical approximation for the location of the towers of Figures 9 and 17. 


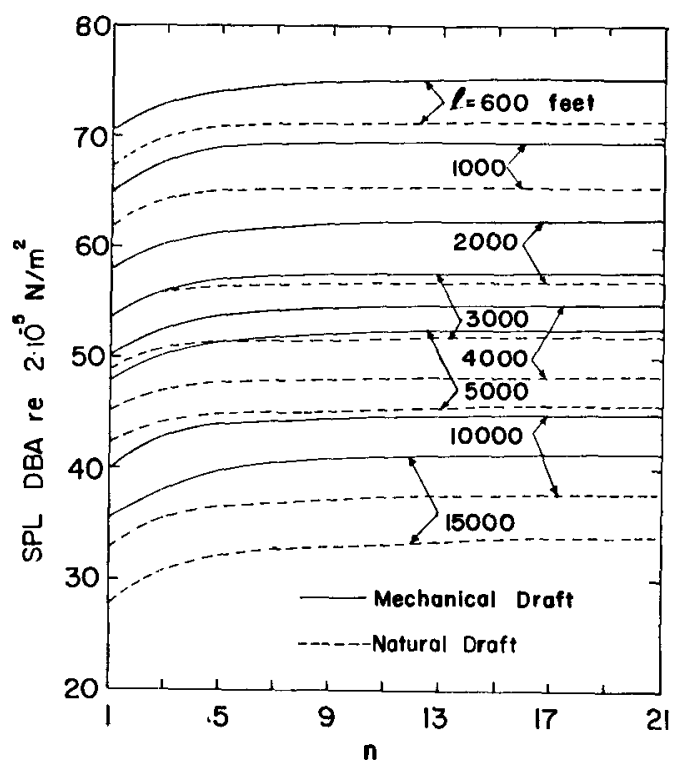

Figure 18. Sound levels at the point $0^{\prime}$ (Figure 17) due to a dispersed array of natural- and mechanicaldraft, towers.

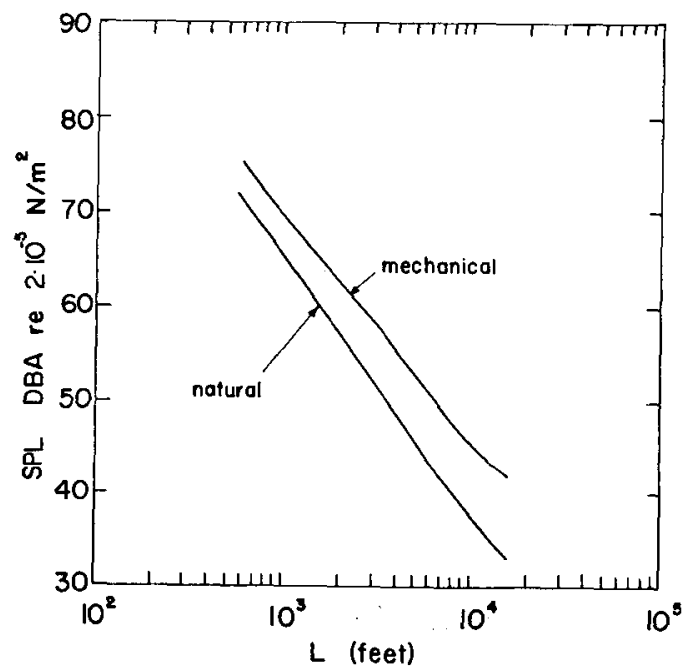

Figure 19. Change of noise levels at the point $0^{\prime}$ with $L$ for the configuration of the dispersed tower sources of Figure $17, n=15$. 


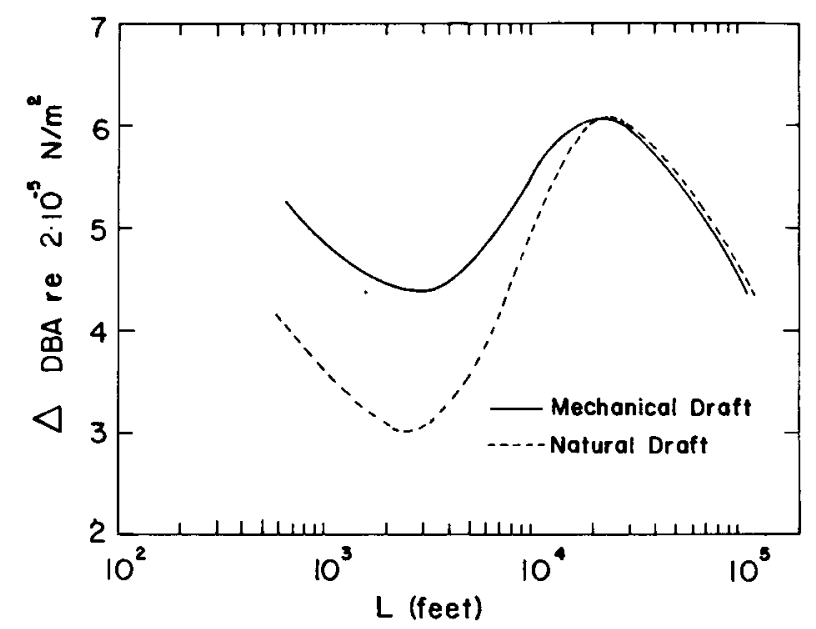

Figure 20. The quantity $\Delta$ obtained from Eq. 43 is plotted against $L$ for the configuration of Figure 17. The value of $\mathrm{n}$ is 15 .

Example 4.4:

Suppose we are given the actual physical situation of Figure 9 . Keeping the location of the nearest four towers from the point 0 fixed, the corresponding $\mathrm{L}$, using the simplified analysis of this section, will be

$$
\mathrm{L}=\frac{\ell}{2 \cos 45} \text {. }
$$

For example if $\ell=1,000 \mathrm{ft}$, L will be $707 \mathrm{ft}$. From Figure 12 for an $\ell$ of 1,000 ft, we will predict $70 \mathrm{DBA}$ for natural and $73.7 \mathrm{DBA}$ for mechanical-draft towers. From Figure 19 for an L of $707 \mathrm{ft}$, the corresponding numbers are 69.5 and 73.6 respectively. For $\ell=10,000 \mathrm{ft}$, $\mathrm{L}$ will be 7,070 ft, and we read the following data from Figures 12 and 19:

Table 10

Comparison of the Predicted Results by Using the Dispersed Tower Array Approximations of Figures 9 and 17

\begin{tabular}{llc}
$\begin{array}{l}\text { Type of } \\
\text { Towers }\end{array}$ & $\begin{array}{l}\ell=10,000 \mathrm{ft} \\
\text { (Figure 12) }\end{array}$ & $\begin{array}{l}\mathrm{L}=\ell / 2 \cos 45=7,070 \mathrm{ft} \\
\text { (Figure 19) }\end{array}$ \\
\cline { 2 - 3 } $\begin{array}{l}\text { Mechanical } \\
\text { Natural }\end{array}$ & $47.3 \mathrm{DBA}$ & $48.7 \mathrm{DBA}$ \\
& $40.0 \mathrm{DBA}$ & $37.8 \mathrm{DBA}$
\end{tabular}

For most purposes, it seems that one may use either of the two geometrical descriptions (Figure 9 or 17) for a homogeneous array. 
Consider first the noise levels within the area of the energy center, given a total capacity of $48 \mathrm{GW}$, and with 80 cooling towers. These towers can be assumed to be uniformly distributed over the area of the energy center illustrated in Figure 6, and their locations can be approximated by the geometry of Figure 10. It should be noted that a total of 80 grid points, each of which will represent the location of one tower around the point 0 in Figure 10, cannot be obtained by taking either $n$ equal to 4 or 5 . The computation of the noise levels at the point 0 has therefore to be done by averaging the results for $n=4$ and $n=5$.

The overall picture of the location of the towers will be as shown in Figure 21. It should be recalled that the maximum radii $r$ for which noise levels at any point on the site boundary will not exceed 45 DBA re $2 \cdot 10^{-5} \mathrm{~N} / \mathrm{m}^{2}$, were predicted to be 17,500 and $24,500 \mathrm{ft}$ for mechanicaland natural-draft towers respectively. It can be estimated from the geometry of Figure 21 that a radius $r$ of $17,500 \mathrm{ft}$ corresponds to an $l$ of 3,500 ft for mechanical-draft towers. For natural-draft towers, for an $\mathrm{r}$ of $24,500 \mathrm{ft}$ the value of $l$ will be 4,900 ft. We now look at Figure $22^{*}$ which shows the variation of noise levels at the point 0 (Figure 21) with $\ell$. By the help of this figure and Figure 11, we can easily predict the minimum noise levels which can be expected within the area of the power park. For an $\ell$ of 3,500 ft for mechanical-draft towers, this minimum level will be $57 \mathrm{DBA}$. This number will be 48.3 for naturaldraft towers for an $\ell$ of $4,900 \mathrm{ft}$.

We sha11 now illustrate an example for finding the noise levels at the site boundary, and the minimum noise levels within the area of the energy center, given the value of $r$.

\footnotetext{
* The data for this figure was obtained by taking the average of the results with $\mathrm{n}=4$ and $\mathrm{n}=5$.
} 


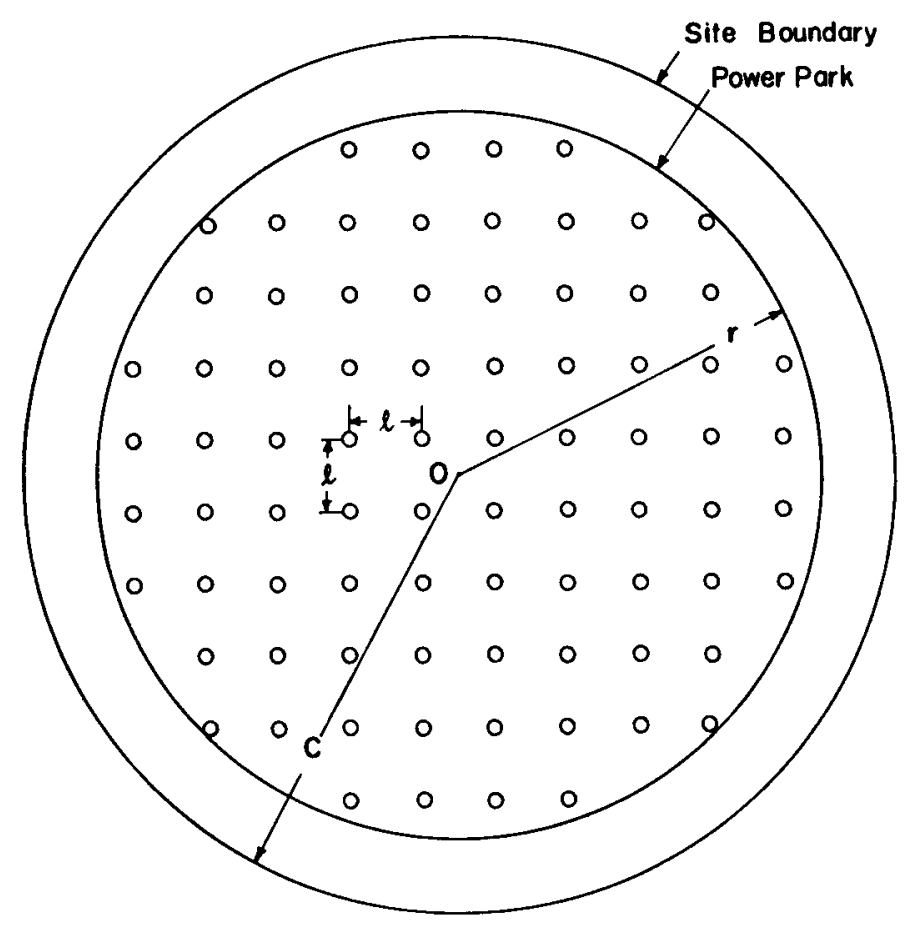

Figure 21. Location of towers within the power park. For a site area of 75 square miles the value of $C$ will be $25,800 \mathrm{ft}$.

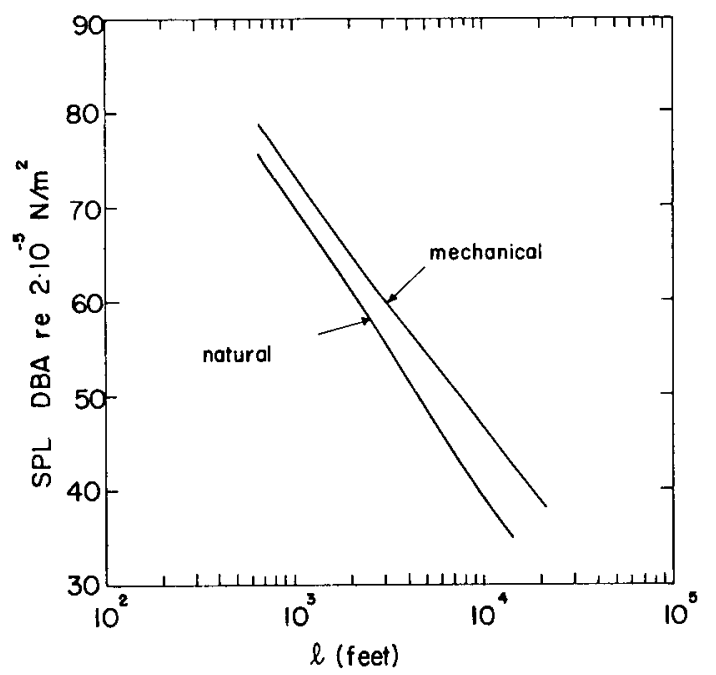

Figure 22. Change of noise levels at the point 0 of Figure 21 with $\ell$. This data has been averaged for $\mathrm{n}=4$ and $\mathrm{n}=5$. 
Example 5.1:

Let $r=15,000 \mathrm{ft}$ and $\ell \simeq \mathrm{r} / 5=3,000 \mathrm{ft}$. From Figure 22 we read the following data presented in Table 11 for $\ell=3,000 \mathrm{ft}$.

Table 11

Prediction of SPL at the Center of the Energy Center

(Point 0 of Figure 21)

$$
l=3,000 \mathrm{ft}, \quad \mathrm{r}=15,000 \mathrm{ft}, \quad \mathrm{n}=4.5
$$

Type of Towers

Noise Levels at 0 from Figure 21

Mechanical DBA re $2 \cdot 10^{-5} \mathrm{~N} / \mathrm{m}^{2}$

Natural

60.0

55.3

From Figure 11, for $\mathrm{n}=4.5$ and $\ell=3,000 \mathrm{ft}$, the values of $\Delta$ will be approximately $2 \mathrm{DBA}$ and $1.3 \mathrm{DBA}$ for mechanical- and natural-draft towers respectively. The minimum noise levels within the area of the energy center can now be predicted as shown in Table 12 .

Table 12

Prediction of Minimum Noise Levels in the Energy Center
$\ell=3,000 \mathrm{ft}$,
$r=15,000 \mathrm{ft}$,
$\mathrm{n}=4.5$

Type of Towers

Minimum Noise Levels

Mechanical

DBA re $2 \cdot 10^{-5} \mathrm{~N} / \mathrm{m}^{2}$

Natural

$\sim 60-\Delta / 2=59$

$\sim 55.3-\Delta / 2=54.7$

Next we can predict the noise levels at the site boundary from Figure 8 . 


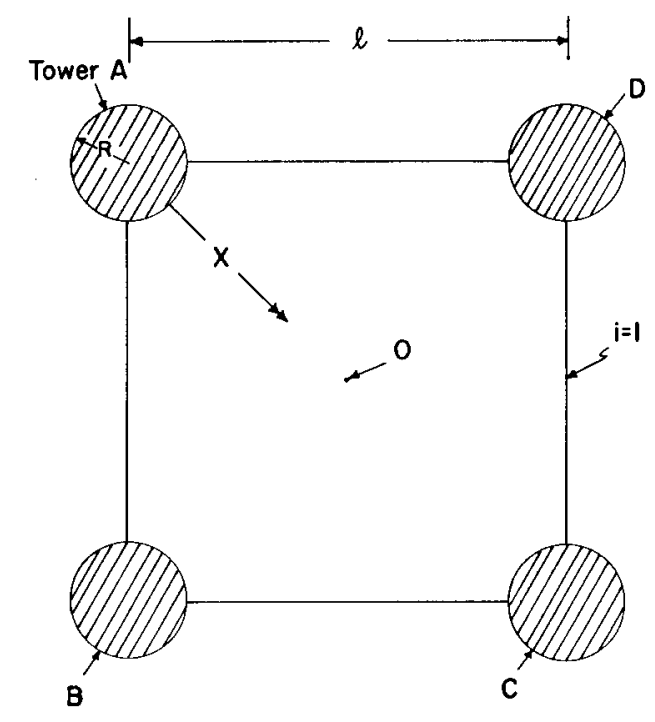

Figure 23. Diagonal distance $X$ from the rim of the tower. This distance for a fixed DBA is plotted against $\ell$ in Figure 24.

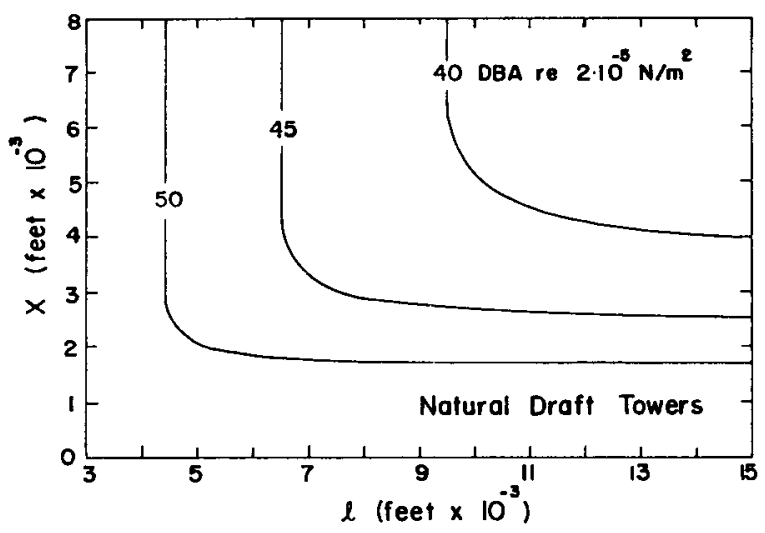

Figure 24. Change of the diagonal distance $X$ from the rim of the natural-draft tower (Figure 23) at which the noise levels of 40,45 and $50 \mathrm{DBA}$ will be reached, has been plotted against $\ell$. 


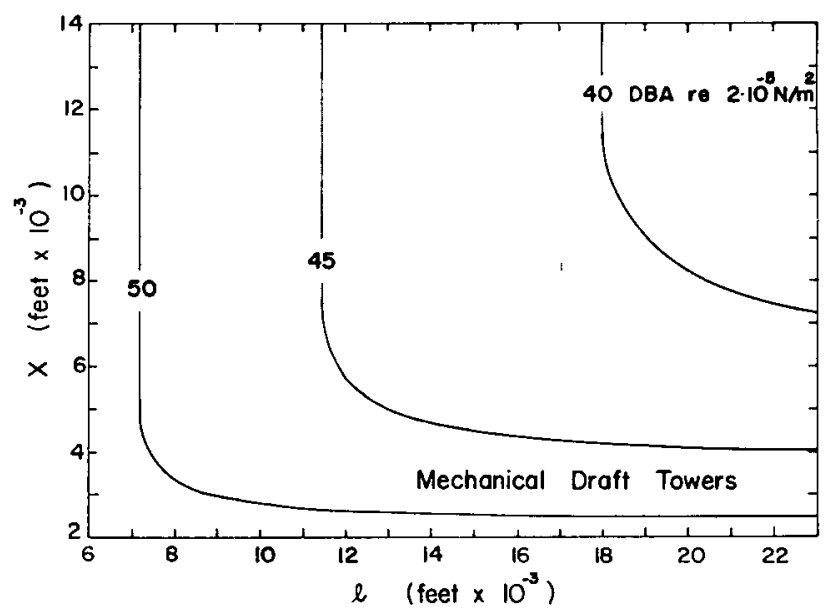

Figure 25. Change of the diagonal distance $X$ from the rim of the mechanical-draft tower (Figure 23), at which the noise levels of 40,45 and 50 DBA will be reached, has been plotted against $\ell$.

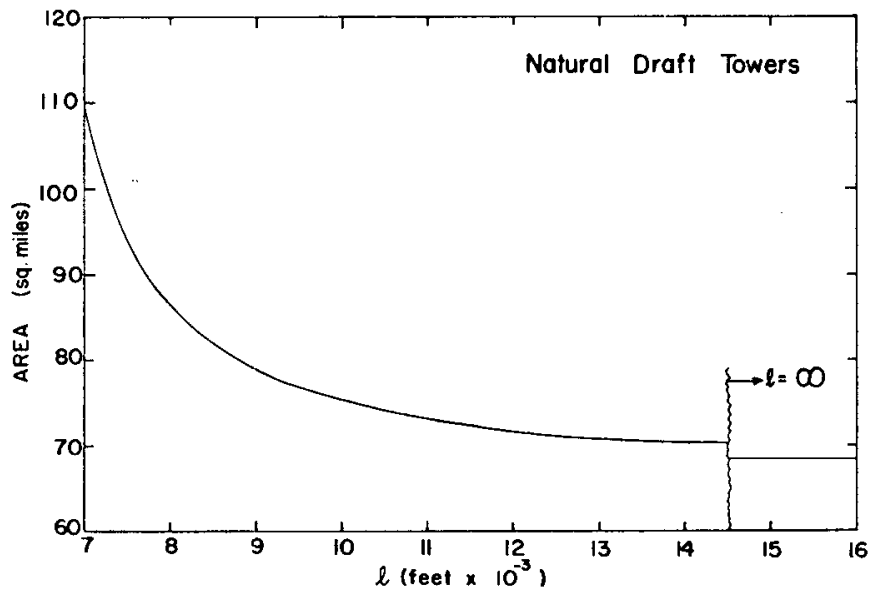

Figure 26. Total area of the dispersed sites of eighty $600 \mathrm{MW}$ power stations with natural-draft cooling towers. Noise levels will always be greater than 45 DBA within this area. 




Figure 27. Total area of the dispersed sites of eighty $600 \mathrm{MW}$ power stations with mechanical-draft cooling towers. Nolse levels will always be greater than $45 \mathrm{DBA}$ within this area.

Table 14

Estimation of Eighty Dispersed $600 \mathrm{MW}$ Power Station Sites

Given $\ell$, SPL exceeding 45 DBA are unacceptable

Type of Towers

Mechanical

Natural

\section{$x$}

(ft) given

14,000

$\infty^{*}$

14,000

$\infty$ (ft)

Figure 24

4,670

3,800

2,600

2,500
$\mathrm{X}+\mathrm{R}$

(ft)

4,870

4,000

2,800

2,700
$\pi\left(\frac{\mathrm{X}+\mathrm{R}}{5280}\right)^{2} \times 80$

sq. miles

214.1

144.24

70.68

65.72

${ }^{*} \ell=\infty$ means that effects of all the other towers have to be neglected. The corresponding data for $X$ has been recorded from Figure 2 . 
Table 13

Prediction of SPL at the Energy Center Site Boundary for a

Given $\mathbf{r}$

Type of Towers

Mechanical

Natural
Noise Levels at some Point on the Site Boundary (DBA re $2 \cdot 10^{-5} \mathrm{~N} / \mathrm{m}^{2}$ )

44.0

36.5

Consider next the case of increasing dispersion. We are removing the restriction of the site boundary, and increasing $r$ to such values that noise levels within the area over which the towers are spread, fall below 45 DBA and are hence acceptable. The distances X (Figure 23) from the rim of the towers at which noise levels will reach 40, 45 and $50 \mathrm{DBA}$, have been plotted against $\ell$ in Figure 24 . It should be noted that as $\ell$ is increased, $X$ decreases, and so does the area affected by noise. Considering that noise levels of below 45 DBA are generally acceptable, we can estimate the area of the site for each 600 MWe generating station. Figures 26 and 27, constructed for natural-and mechanical-draft towers respectively, show the total area in which the noise levels will exceed $45 \mathrm{DBA}$. This total area is, of course, associated with a power generation of $48 \mathrm{GW}(\mathrm{e})$, and should be studied in comparison with the area of the power park site of $75 \mathrm{sq}$. miles. The estimation of the areas of Figure 26 has been presented in an example illustrated below:

Example 5.2:

Suppose $\ell=14,000 \mathrm{ft}$ and $\infty$. It should be recalled that a mechanical-draft tower was assumed to occupy the same ground area if substituted for a natura1-draft tower. The radius $\mathrm{R}$ for a typical natural-draft tower for a 600 MW power station was stated in Section 2.1 to be $200 \mathrm{ft}$. We thus construct the following table: 
It is worth noting from Figure 26 that for natural-draft towers an $\ell$ of $10,250 \mathrm{ft}$ yields an area of $75 \mathrm{sq}$. miles over which noise levels will always exceed $45 \mathrm{DBA}$. This $\&$ thus corresponds to the area of the alternative energy center site. Decreasing $\ell$ will increase the total area of the 80 sites quite rapidly, and will thus be undesirable. Increasing $\ell$ beyond $10,250 \mathrm{ft}$ will certainly decrease this area but not dramatica11y.

On the other hand, for mechanica1-draft towers, from Figure 27 we note that no matter how large we make the $\ell$, the total affected area will always be above $150 \mathrm{sq}$. miles. Thus, this affected area will always be more than twice the site area of the alternative concentrated energy center. 
Chapter 6

CONCLUSIONS

1. Stating the conclusions for the single isolated cooling towers for a $600 \mathrm{MW}$ power station, in Chapter 2 we saw that mechanical-draft towers will be noisier than their natural-draft counterparts. For moderate distances from the tower we may generalize that the mechanical-draft systems will be about 4 DBA louder. The acoustic power generated from the mechanical-draft tower under consideration was shown in Chapter 2 to be twice of that from the natural-draft tower for a $600 \mathrm{MW}$ station. Knowing that sound levels of below 45 DBA are generally acceptable, it will be interesting to note the distances from the tower rim at which this level is reached. These distances from Figure 2 will be 2,500 and 3,800 ft for natural- and mechanical-draft towers respectively. These will therefore be the safe distances from single isolated towers ${ }^{*}$ at which noise levels are not likely to pose any problem.

2. For concentrated power centers we found in Chapter 3 that for some range of power park radius $r$, Figure 6 , noise levels at the site boundary will not exceed $45 \mathrm{DBA}$, and hence will be acceptable. These energy center radii from Figure 8 are 17,500 and 24,000 ft for mechanicaland natural-draft tower systems respectively.

3. Last but not least, we compare the results for the concentrated energy center with the randomly dispersed array of electric generating stations. The basis of comparison is the area affected by a level of noise from the cooling towers exceeding $45 \mathrm{DBA}$. With natural-draft towers, in the limit of infinitely wide dispersion, the area impacted by noise levels of $45 \mathrm{DBA}$ or higher is about the same as the corresponding concentrated energy center. In the case of mechanical-draft towers, in the limit of infinitely wide dispersion, this impacted area is about twice the corresponding park area of 75 square miles.

${ }^{*}$ See Figures 1 and 2 for relevant tower parameters. 
Hence we conclude that if concentrated energy centers are chosen, and judged by noise at the boundary of 75 square mile sites, then either mechanical- or natura1-draft towers may be used. In the case of naturaldraft systems, however, a somewhat greater degree of dispersion within the 75 square mile site area will be possible. On the other hand, if more widely dispersed energy centers are destrable, then naturaldraft systems should be chosen if one wishes to minimize the total area impacted by objectionable noise. Conversely, if mechanical-draft towers are to be employed, then concentrated energy centers would provide the least area impacted by unacceptable noise due to cooling systems. 


\section{APPENDIX}

DISCUSSION OF THE FORM OF $\triangle$

An important conclusion to be drawn from Figure 11 is that increasing $n$ has but little effect on noise levels at the point 0 . This effect, plotted in the form of $\Delta$ in Figure 13 attains its maximum at an $\ell$ of about 30,000 ft, beyond which it decreases uniformly, eventually approaching zero at very large $\ell$. The curves for mechanical- and natural-draft towers are almost identical for $\ell$ greater than 30,000 ft. For smaller $\ell$, however, the difference between the values of $\Delta$ for the two types of dispersed tower sources is worth noting and is obviously due to the difference in the respective noise spectra. In order to further comprehend the oscillating behavior of $\Delta$ with $\ell$ for the values below about 30,000 ft, we should now discuss Figure 20, which exhibits similar trends as Figure 13. As we look at the numerator of $\mathrm{Eq}$. (44) we realize that for some band number $\mathrm{p}$, i.e., for $\mathrm{p}=1$ thru $\mathrm{k}$, the following quantity

$$
10^{-0.1 A_{p}}-b_{p} i L
$$

will become maximum for $i$ and $L$ fixed. Similarly, for this $p$, the following term will be minimum:

$$
0.1 A_{p}+b T_{p} i L
$$

But when we are summing Eq. (48) for $p=1,2, \ldots \ldots, \mathrm{k}$, i.e.

$$
\sum_{p=1}^{k} 10^{-0.1 A_{p}-b T_{p} i L}
$$

The most important contribution to the magnitude of the summation will be the value of that term of the summation which is maximum out of a total of $k$ terms. Now, when $i$ and $L$ are changed, (48) might attain its 
maximum at another $p$, which will eventually affect the magnitude of the summation (50) as already explained. The fact that as $i$ and $L$ are increased the quantity (48) attains its maximum at a different $p$, characterizes what we might call a fluctuating behavior of $\Delta$ with either $\ell$ or L.

At large $\mathrm{L}$, the first term of the quantity (49) will become relatively insignificant compared to the magnitude of the term $b_{p} i L$, even for the smallest of $\mathrm{T}_{\mathrm{p}}$ in the spectrum. Under such circumstances it can easily be shown that eq. (44) can be approximately represented as:

$$
\Pi=\sum_{i=1}^{n} \frac{2 i-1}{i^{2}} 10^{b T} p^{L}(1-i)
$$

where $T_{p}$ in Eq. (51) must be the minimum value of $T_{p}$ for $p=1,2, \ldots . k$. For example from Table 9, this value of $\mathrm{T}_{\mathrm{p}}$ will be .0049

and .000793 for natural- and mechanical-draft towers respectively. From Eq. (51) the following result immediately follows:

$$
\frac{d \Pi}{d L} \sim \sum_{i=1}^{n} \frac{2 i-1}{i^{2}} b T_{p}(1-i) e^{b t_{p} L(1-i)}
$$

The right hand term in Eq. (52) will always be $\leq 0$ for all $i \geq 1$. It can also be shown from Eq. (51) that for very large $L$ we have

$$
\pi \sim \frac{1}{\mathrm{~L}}
$$

Hence $\Pi$, and consequently $\Delta$, will uniformly approach zero for $L$ tending to infinity.

We can summarize our discussion about the behavior of $\Delta$ by saying that as the degree of dispersion of towers is increased from lower values, $\Delta$ increases or decreases depending on how various frequencies in the noise spectrum are affected by attenuation due to the atmosphere and A-weighting. The value of $\Delta$ will reach its maximum for some degree of dispersion of the tower array. Beyond this maximum $\Delta$ will gradually approach the value 
of zero mainly because of atmospheric absorption at lower frequencies.

It is also interesting to note from Figures 13 and 20 that mechanicaldraft towers which are already known to be noisier when considered in the form of a dispersed array. This conclusion, of course, applies exclusively for values of $\ell$ below about 30,000 ft for the square geometry, and an L of below 20,000 ft for the circular geometry. Beyond these ranges, however, the total affect of dispersed tower sources will be the same for the two types of cooling systems. 
1. Dickey, J.B., Jr., and Cates, R.E., "Managing Waste Heat with the Water Cooling Tower", 2nd Ed., The Marley Co., April 1973.

2. McKelvey, K.K., and Maxey Brooke, "Cooling Tower", Elsevier Publishing Co., 1959.

3. Ellis, R.M., "Cooling Tower Noise Generation and Radiation", J. Sound Vib., pp. 171-182, Vo1. 14(2), 1971.

4. Beranek, L.L., "Noise and Vibration Control", McGraw Hill Book Co., 1971.

5. Dyer, I., and Miller, L.N.,"Cooling Tower Noise", J. Noise Control, Vo1. 5, No. 3, 1959.

6. Broch, J.T., "Acoustic Noise Measurements", Bruel and Kjaer, 1971.

7. "Heat Sink Design and Cost Study for Fossil and Nuclear Power Plants", Div. Reactor Res. and Dev., U.S. AEC, Wash-1360, Dec. 1974.

8. Capano, G.A., and Bradley, W.E.,"Radiation of Noise from Large Natura1 Draft and Mechanical Draft Cooling Towers", ASME, 74-WA/HT-55.

9. "Noise-Con 73", National Conference on Noise Control Engineering, Wash., D.C., p. 433-438, Oct. 15-17, 1973.

10. "Summary of Noise Programs in the Federal Government" U.S. Env. Protection Agency, Wash., D.C., HUD, p. 8, Dec. 31, 1971. 